\title{
Colobopsis explodens sp. n., model species for studies on "exploding ants" (Hymenoptera, Formicidae), with biological notes and first illustrations of males of the Colobopsis cylindrica group
}

\author{
Alice Laciny ${ }^{1,2}$, Herbert Zettel', Alexey Kopchinskiy ${ }^{3}$, Carina Pretzer ${ }^{3}$, Anna Pal', \\ Kamariah Abu Salim ${ }^{4}$, Mohammad Javad Rahimi ${ }^{3}$, Michaela Hoenigsberger ${ }^{5}$, \\ Linda Lim $^{6}$, Weeyawat Jaitrong ${ }^{7}$, Irina S. Druzhinina ${ }^{3}$
}

I $2^{\text {nd }}$ Zoological Department, Natural History Museum Vienna, Burgring 7, 1010 Vienna, Austria 2 Department of Theoretical Biology, Althanstraße 14, 1090 Vienna, Austria 3 Research Area Biochemical Technology, Institute of Chemical, Environmental and Biological Engineering, TUWien, Gumpendorfer Straße 1a, 1060 Vienna, Austria 4 Environmental and Life Sciences, Universiti Brunei Darussalam, Jalan Tungku Link, Bandar Seri Begawan BE 1410, Brunei Darussalam 5 Center for Analytical Chemistry, Department of Agrobiotechnology, University of Natural Resources and Life Sciences, Vienna (BOKU), Konrad-Lorenz-Straße 20, 3430 Tulln, Austria 6 Chemical Sciences, Universiti Brunei Darussalam, Jalan Tungku Link, Bandar Seri Begawan, BE 1410, Brunei Darussalam 7 Thailand Natural History Museum, National Science Museum, Technopolis, Khlong 5, Khlong Luang, Pathum Thani, 12120 Thailand

Corresponding author: Alice Laciny (alice.laciny@nhm-wien.ac.at)

Academic editor: M. Borowiec | Received 30 November 2017 | Accepted 26 February 2018 | Published 19 April 2018

http://zoobank.org/FB03088D-5382-44B4-B518-04E30F172EC8

Citation: Laciny A, Zettel H, Kopchinskiy A, Pretzer C, Pal A, Salim KA, Rahimi MJ, Hoenigsberger M, Lim L, Jaitrong W, Druzhinina IS (2018) Colobopsis explodens sp. n., model species for studies on "exploding ants" (Hymenoptera, Formicidae), with biological notes and first illustrations of males of the Colobopsis cylindrica group. ZooKeys 751: 1-40. https://doi.org/10.3897/zookeys.751.22661

\begin{abstract}
A taxonomic description of all castes of Colobopsis explodens Laciny \& Zettel, sp. n. from Borneo, Thailand, and Malaysia is provided, which serves as a model species for biological studies on "exploding ants" in Southeast Asia. The new species is a member of the Colobopsis cylindrica (COCY) group and falls into a species complex that has been repeatedly summarized under the name Colobopsis saundersi (Emery, 1889) (formerly Camponotus saundersi). The COCY species group is known under its vernacular name "exploding ants" for a unique behaviour: during territorial combat, workers of some species sacrifice themselves by
\end{abstract}

Copyright Alice Laciny et al. This is an open access article distributed under the terms of the Creative Commons Attribution License (CC BY 4.0), which permits unrestricted use, distribution, and reproduction in any medium, provided the original author and source are credited. 
rupturing their gaster and releasing sticky and irritant contents of their hypertrophied mandibular gland reservoirs to kill or repel rivals. This study includes first illustrations and morphometric characterizations of males of the COCY group: Colobopsis explodens Laciny \& Zettel, sp. n. and Colobopsis badia (Smith, 1857). Characters of male genitalia and external morphology are compared with other selected taxa of Camponotini. Preliminary notes on the biology of $C$. explodens Laciny \& Zettel, sp. n. are provided. To fix the species identity of the closely related C. badia, a lectotype from Singapore is designated. The following taxonomic changes within the C. saundersi complex are proposed: Colobopsis solenobia (Menozzi, 1926), syn. n. and Colobopsis trieterica (Menozzi, 1926), syn. n. are synonymized with Colobopsis corallina Roger, 1863, a common endemic species of the Philippines. Colobopsis saginata Stitz, 1925, stat. n., hitherto a subspecies of $C$. badia, is raised to species level.

\section{Keywords}

autothysis, behavioural ecology, Camponotini, Colobopsis, Formicidae, integrative taxonomy, male morphology, molecular biology, morphometry, new species, new status, new synonymy, phylogeny, Southeast Asia, taxonomy

\section{Introduction}

The Colobopsis cylindrica (COCY) group likely represents a monophyletic clade containing Southeast Asian ant species with distinctive hypertrophied mandibular gland reservoirs. In territorial combat, minor workers use the sticky and irritant contents of their enlarged mandibular gland reservoirs to kill or repel rival arthropods. In species where this defensive behaviour is more advanced, this happens via the characteristic suicidal "exploding" by voluntary rupture of the gastral integument (autothysis) (Cook 2008). This behaviour was first mentioned by Viehmeyer as early as 1916, and subsequently described in detail by Maschwitz and Maschwitz (1974), as well as Davidson et al. (2012), and Shorter and Rueppell (2012).

The Bornean members of the COCY group have been the subject of various ecological (e.g., Cook 2008, Davidson et al. 2007, 2009, 2016), morphological (Davidson et al. 2012, Laciny et al. 2017) and chemical (Jones et al. 2004, Hoenigsberger et al. in prep.) studies in the past. Based on the results of previous investigations, in 2014 an interdisciplinary research project started to explore the evolution and ecological significance of autothysis in the COCY group. From the surroundings of the Kuala Belalong Field Studies Centre (KBFSC) in Brunei, at least 15 species are known (Davidson et al. 2007), most of which are probably new to science. One species, previously referred to as "yellow goo" (Davidson et al. 2007) or "YG" (Davidson et al. 2016) for the bright yellow colour of its mandibular gland secretion, was found to have a large colony just at the KBFSC. As this abundant species frequently exhibits characteristic autothysis behaviour and can be observed in situ and in vitro, it became the main object of behavioural and chemical experiments, and a model species for biological studies on "exploding ants". Preliminary taxonomic and molecular analyses revealed that this morphospecies is in fact an undescribed species. As the revision of the COCY group is still ongoing (I. Druzhinina et al. in prep.), the aim of this paper is to provide a 
valid name, Colobopsis explodens Laciny \& Zettel, sp. n., for subsequent use in the various behavioural, chemical, microbiological, and evolutionary publications currently in preparation. Within this study, we employ the multidisciplinary concept of integrative taxonomy (sensu Schlick-Steiner et al. 2010) by combining morphometric, ecological, and molecular data. We provide a taxonomic description of all castes of Colobopsis explodens sp. n. including males. Illustrations and morphometric characterizations of males of the COCY group had not been previously published. We compare males of Colobopsis explodens sp. n. with the newly illustrated male of C. badia (Smith, 1857) to highlight species-specific characters in the complex. Morphological characters of the male, including genitalia, are also compared with other selected taxa of Camponotini. Based on field observations, the first records on the natural history and biology of Colobopsis explodens sp. n. are provided.

\section{Materials and methods}

\section{Sampling-sites and imaging of living ants}

The primary field research took place in the lowland dipterocarp rainforest at the Kuala Belalong Field Studies Centre (KBFSC), Temburong District, Brunei Darussalam ( $\left.4^{\circ} 32^{\prime} 48.2^{\prime \prime} \mathrm{N}, 115^{\circ} 09^{\prime} 27.9^{\prime \prime} \mathrm{E}\right)$, where Colobopsis explodens sp. n. was sampled during five collecting trips (each of 30 days duration) encompassing different seasons from 2014 to 2016.

The behaviour of $C$. explodens sp. n. was observed at multiple nesting sites on several height-levels, starting from the forest floor and understory up to the canopy and emergent layer. The activity of ants was recorded in situ and in vitro using a CANON 70D Digital SLR Camera with a CANON EF $100 \mathrm{~mm}$ macro lens and a Tamron AF 28-200 mm F/3.8-5.6 XR Di aspherical (IF) macro zoom lens (Suppl. material 2: S2a). For macro and close-up filming the Neewer adjustable LED light with LCD display was used. When necessary, the camera was mounted with the use of a Manfrotto Gorillapod 494RC2 tripod. The movie (Suppl. material 7) was annotated and cut using Corel VideoStudio X10 Software.

Sampling of Colobopsis badia in southern Thailand was conducted by H. Zettel and W. Jaitrong in June 2016. The sampling site was located in the Khao Chong Botanical Garden, near the Ton Pliw Waterfall $\left(07^{\circ} 32^{\prime} 34^{\prime \prime N}, 99^{\circ} 47^{\prime} 33^{\prime \prime E}\right)$; a single male specimen was caught at a light at the Botanical Garden headquarters.

\section{Host trees and activity assessment}

Nesting habits of $C$. explodens sp. n. were observed based on the model colony occupying several trees and an artificial nest (nest \#38, Fig. 9) in direct vicinity to the kitchen facility at KBFSC. The artificial nest consisted of a $100 \mathrm{~cm}$ tall and $6 \mathrm{~cm}$ wide square wooden stake, 
with a cavity of approximately $15 \mathrm{~mm}$ in diameter drilled into the centre and a $4 \mathrm{~mm}$ wide entrance hole in the top third of the stake. The nest was painted with green acrylic paint and fastened to a small tree with rope (for detailed method of construction, see Davidson et al. 2009 and Laciny et al. 2017). The host trees were identified by comparison with type samples preserved in the herbarium of Universiti Brunei Darussalam, Brunei. The main host tree was DNA barcoded (see Suppl. material 6 “accession numbers”).

The activity of $C$. explodens sp. n. occupying artificial nest \#38 was observed from $14^{\text {th }}$ to $30^{\text {th }}$ November of 2015 at different times during the day, for 30 minutes each by counting the ants entering and leaving the nest. Temperature, barometric pressure, and weather conditions were recorded, as well as any observed noteworthy behaviour (see Fig. 9; Suppl. material 6 "activity").

\section{DNA Extraction, PCR amplification, and Sanger sequencing}

DNA extraction, gene fragment amplification, and sequencing were performed for minor worker ants of five different taxa (C. explodens sp. n., C. badia, C. nr. saundersi, C. aruensis Karawajew, 1933, and C. cylindrica (Fabricius, 1798)), as well as for mandibular gland reservoir content of $C$. explodens sp. n., one symbiotic cricket (Camponophilus sp.) from artificial nest \#38, and the host plant of C. explodens sp. n. (Shorea johorensis).

For DNA barcoding of ant specimens, DNA was extracted from ant legs using Qiagen's tissue QIAamp DNA Micro kit following the manufacturer's protocol (Qiagen, Venlo, Netherlands). To obtain sufficient DNA quantity for further processing, the amount of legs used per sample varied. For the DNA extraction of queens, a minimum of three legs of one individual were transferred into one $1.5 \mathrm{ml}$ microcentrifuge tube and frozen with liquid nitrogen. Three legs of one individual was also the minimum amount for males and major workers. For minor workers, all legs from two to four individuals were pooled (see Suppl. material 6 "accession numbers"). The frozen legs were ground into small pieces with disposable pestles attached to a pestle motor (Kimble, Vineland, NJ, USA). Subsequent steps were performed according to manufacturer's instructions with the following exceptions: sample lysis for 20 hours, final elution step with 25-50 $\mu$ l elution buffer. To assess the purity of the extraction, DNA concentration and 260/280 nm ratio were measured with a NanoDrop ND-1000 Spectrophotometer (Software Version ND-1000 v.3.8.1, Thermo Fisher Scientific, MA, USA).

For DNA barcoding of symbiotic crickets, DNA was extracted from one whole specimen applying the same procedure as used for ants legs, but with a pretreatment with an enzymatic lysis buffer (Tris. $\mathrm{Cl} 20 \mathrm{mM}$, pH 8.0, sodium EDTA $2 \mathrm{mM}$, Triton $\mathrm{X}-1001.2 \%$, add lysozyme to $20 \mathrm{mg} / \mathrm{ml}$ for $60 \mathrm{~min}$ ).

For DNA barcoding of the host plant, $100 \mathrm{mg}$ of a leaf were ground with mortar and pestle under the use of liquid nitrogen and DNA was extracted using Qiagen's DNeasy Plant Mini Kit according to manufacturer's instructions.

For the ants, the gene fragments cytochrome $\mathrm{C}$ oxidase subunit I and II (COI, COII), cytochrome B (cytB), and carbamoyl-phosphate synthase II (cad) were am- 
plified, for the cricket only COI. Additionally, a fragment of $16 \mathrm{~S}$ rRNA was amplified from the DNA extracted from the mandibular gland content of C. explodens sp. n. minor workers, to assess the presence of bacteria. For the plant, the gene fragment maturase K (matK) was amplified. Primer sequences and specific annealing temperatures are given in Tab. 1. Final concentrations for PCR were 1× GoTaq Flexi Buffer (Promega, Madison, Wisconsin, USA), 0.16 mM dNTP's, 3 mM MgCl (Promega), $0.4 \mu \mathrm{M}$ forward and reverse primer (Microsynth, Balgach, Switzerland), 0.8 Units GoTaqG2 Flexi polymerase (Promega) and 2-50 ng sample (diluted with HPLC water, ROTH), in a final volume of $50 \mu \mathrm{l}$. PCR was performed with a Biometra T3 Thermocycler (Biometra, Göttingen, Germany) with the following conditions: 2 min at $94^{\circ} \mathrm{C}, 35$ cycles of $1 \mathrm{~min}$ at $94^{\circ} \mathrm{C}, 1 \mathrm{~min}$ at primer specific annealing temperature, $90 \mathrm{sec}$ at $72{ }^{\circ} \mathrm{C}$ and finally $7 \mathrm{~min}$ at $72{ }^{\circ} \mathrm{C}$. PCR products were separated by $1.5 \%$ agarose gel electrophoresis. PCR products were purified using mi-PCR Purification Kit (Metabion, Planegg, Germany) and one direction sequencing was performed at Microsynth (Austria).

Sequences are deposited in NCBI GenBank. Accession numbers for ant specimens are given in Table 2; see Suppl. material 6 "accession numbers" for additional details.

Table I. Primers used in this study.

\begin{tabular}{|c|c|c|c|c|c|c|c|}
\hline Gene & Name & Sequence $5^{\prime}-3^{\prime}$ & $\begin{array}{l}\text { Length } \\
{[\mathrm{bp}]}\end{array}$ & $\begin{array}{l}\text { GC con- } \\
\text { tent }[\%]\end{array}$ & $\begin{array}{c}\text { Fragment } \\
\text { Length }[\mathrm{bp}]\end{array}$ & $\begin{array}{l}\text { Annealing } \\
\text { Temp }\left[{ }^{\circ} \mathrm{C}\right]\end{array}$ & Reference \\
\hline \multirow{2}{*}{ COI } & LCO1490-F & $\begin{array}{l}\text { GGTCAACAAATCAT- } \\
\text { AAAGATATTGG }\end{array}$ & 25 & 32 & \multirow{2}{*}{709} & \multirow{2}{*}{45} & \multirow{2}{*}{$\begin{array}{l}\text { Chen et al. } \\
2013\end{array}$} \\
\hline & HCO2198-R & $\begin{array}{l}\text { TAAACTTCAGGGT- } \\
\text { GACCAAAAAATCA }\end{array}$ & 26 & 35 & & & \\
\hline \multirow{2}{*}{ COII } & J2791-F & $\begin{array}{l}\text { ATACCHCGDCGA- } \\
\text { TAYTCAGA }\end{array}$ & 20 & $40-55$ & \multirow{2}{*}{858} & \multirow{2}{*}{51} & \multirow{2}{*}{$\begin{array}{l}\text { Chen et al. } \\
2013\end{array}$} \\
\hline & H3665-R & $\begin{array}{l}\text { CCACARATTTCW- } \\
\text { GAACATTG }\end{array}$ & 20 & $35-40$ & & & \\
\hline \multirow{2}{*}{ cytB } & CB11400-F & $\begin{array}{l}\text { TATGTACTACCHT- } \\
\text { GAGGDCAAATATC }\end{array}$ & 26 & $35-42$ & \multirow{2}{*}{485} & \multirow{2}{*}{45} & \multirow{2}{*}{$\begin{array}{l}\text { Chen et al } \\
2013\end{array}$} \\
\hline & CB11884-R & $\begin{array}{l}\text { ATTACACCNCCTAA- } \\
\text { TTTATTAGGRAT }\end{array}$ & 26 & $27-35$ & & & \\
\hline \multirow[b]{2}{*}{$\mathrm{cad}$} & CD1423EF & $\begin{array}{l}\text { AGGTRATACRATCG- } \\
\text { GARAGRCCDGA } \\
\end{array}$ & 25 & $40-60$ & \multirow[b]{2}{*}{800} & \multirow[b]{2}{*}{55} & \multirow[b]{2}{*}{$\begin{array}{l}\text { Ward et al. } \\
2010\end{array}$} \\
\hline & CD1910R & $\begin{array}{l}\text { CCGAGRGGRTCRAC- } \\
\text { RTTYTCCATRTTR- } \\
\text { CAYAC } \\
\end{array}$ & 32 & $38-63$ & & & \\
\hline \multirow{2}{*}{ matK } & $472 \mathrm{~F}$ & \begin{tabular}{|l|} 
CCCRTYCATCTG- \\
GAAATCTTGGTTC \\
\end{tabular} & 25 & $44-52$ & \multirow{2}{*}{750} & \multirow{2}{*}{47} & \multirow{2}{*}{$\begin{array}{l}\text { Yu et al. } \\
2011\end{array}$} \\
\hline & $1248 \mathrm{R}$ & \begin{tabular}{|l|} 
GCTRTRATAATGA- \\
GAAAGATTTCTGC \\
\end{tabular} & 26 & $31-38$ & & & \\
\hline \multirow{2}{*}{$\begin{array}{l}16 S \\
\text { rRNA }\end{array}$} & fD1 & $\begin{array}{l}\text { AGAGTTTGATCCTG- } \\
\text { GCTCAG }\end{array}$ & 20 & 50 & \multirow{2}{*}{1500} & \multirow{2}{*}{56} & \multirow{2}{*}{$\begin{array}{l}\text { Weisburg } \\
\text { et al. } 1991\end{array}$} \\
\hline & $\mathrm{rP} 1$ & $\begin{array}{l}\text { ACGGTTACCTTGT- } \\
\text { TACGACTT }\end{array}$ & 21 & 43 & & & \\
\hline
\end{tabular}


Table 2. List of sequence accession numbers in NCBI GenBank. * Nucleotide sequences from NCBI GenBank.

\begin{tabular}{c|l|l|c|c|c|c|c}
\hline TUCIM & Other IDs & \multicolumn{1}{|c|}{ Organism } & ng/ $\boldsymbol{\mu l}$ & COI & COII & cytB & cad \\
\hline 5053 & & C. explodens sp. n. & 14.7 & MF993252 & MF993269 & MF993286 & MF993304 \\
\hline 5056 & & C. explodens sp. n. & 19.7 & MF993253 & MF993270 & MF993287 & MF993305 \\
\hline 5080 & & C. explodens sp. n. & 10.4 & MF993254 & MF993271 & MF993288 & MF993306 \\
\hline 5098 & & C. explodens sp. n. & 8.6 & MF993256 & MF993273 & MF993290 & MF993308 \\
\hline 5104 & & C. explodens sp. n. & 16.6 & MF993257 & MF993274 & MF993291 & MF993309 \\
\hline 5148 & & C. explodens sp. n. & 6 & MF993258 & MF993275 & MF993292 & MF993310 \\
\hline 5185 & & C. explodens sp. n. & 7.3 & MF993259 & MF993276 & MF993293 & - \\
\hline 5205 & & C. explodens sp. n. & 29.8 & MF993260 & MF993277 & MF993294 & MF993311 \\
\hline 6600 & & C. explodens sp. n. & 8 & - & MF993284 & - & - \\
\hline 5855 & & C. explodens sp. n. & 16.9 & MF993262 & MF993278 & MF993297 & MF993314 \\
\hline 5856 & & C. explodens sp. n. & 28.2 & MF993263 & MF993279 & MF993298 & MF993315 \\
\hline 5942 & & C. explodens sp. n. & 34.3 & MF993264 & MF993280 & MF993299 & MF993316 \\
\hline 5943 & & C. explodens sp. n. & 142.1 & MF993265 & MF993281 & MF993300 & - \\
\hline & YG* & C. explodens sp. n. & n.a. & \multicolumn{2}{|c|}{ EF634201 } & - & - \\
\hline 6461 & & C. badia & 21.3 & MF993266 & MF993282 & MF993301 & MF993317 \\
\hline 6463 & & C. badia & 5.4 & MF993267 & MF993283 & MF993302 & MF993318 \\
\hline 6601 & & C. badia & 17.91 & MF993268 & MF993285 & MF993303 & MF993319 \\
\hline 5698 & & C. nr. saundersi & 50.1 & KU975365.1 & KU975366.1 & MF993296 & MF993313 \\
\hline & CH* & C. cf. cylindrica & n.a. & \multicolumn{2}{|c|}{ EF634198 } & - & - \\
\hline 5086 & & C. cylindrica & 26 & MF993255 & MF993272 & MF993289 & MF993307 \\
\hline 5300 & CAMP004 & C. aruensis & 169.1 & MF993261 & - & MF993295 & MF993312 \\
\hline & \multirow{2}{*}{ Cflor36* } & $\begin{array}{l}\text { Camponotus } \\
\text { floridanus }\end{array}$ & n.a. & AY334397 & - & - & - \\
\hline
\end{tabular}

Sequences of non-ant material are deposited under MG582639 for COI of myrmecophilous crickets (Camponophilus sp.), MF993320 for matK of Shorea johorensis and MF996752 for 16S rRNA of cf. Blochmannia (Enterobacteriales).

\section{Phylogenetic analysis}

GapStreeze v. 2.1.0 (https://www.hiv.lanl.gov/content/sequence/GAPSTREEZE/gap. html) was used for COI gene alignment with $95 \%$ gap tolerance in order to retain only the conserved region. The individual gene alignments were subjected to best substitution model selection using the BIC criterion in SMS (Lefort et al. 2017). Consecutively, HKY85, HKY85+I, HKY85+G, and GTR+G were chosen as best substitution models for genes cad, cytB, COI, and COII respectively. The concatenated alignment was partitioned for each locus using MrBayes v. 3.2.5 (Ronquist et al. 2012), and the respective substitution models were assigned to each partition. The substitution and branch length estimates were allowed to vary independently between each partition. Priors for an exponential distribution with mean 1 to all branch lengths and to all shape parameters were assigned for all four partitions. Metropolis-coupled Markov 
chain Monte Carlo (MCMCMC) sampling was performed using MrBayes v. 3.0B4 (Ronquist et al. 2012) with two simultaneous runs of four incrementally heated chains that performed 1 million generations. Bayesian posterior probabilities (PP) were obtained from the $50 \%$ majority rule consensus of trees sampled every 100 generations after removing the first $25 \%$ of trees using the "burnin" command. According to the protocol of Leache and Reeder (2002), PP values higher than 0.94 were considered significant. The phylogenetic trees were visualized in FigTree v. 1.4.3 (Rambaut 2016) and then annotated using vector graphic software.

\section{Morphological methods}

All specimens used for morphometry were card-mounted, individually numbered, and measured at magnifications from 25.6x up to 256x with a Nikon SMZ1500 binocular microscope. Genital structures of two male specimens were dissected and mounted separately. Results represent minimum and maximum values for each morph; in cases where a character could not be measured in all individuals, the number of measured specimens is given in parentheses. The complete dataset of measurements is provided in Suppl. material 6 "measurements".

\section{Measurements and indices $\left(^{*}=\right.$ only gynes and males)}

EL Eye length. Maximum diameter of compound eye, measured in lateral view.

FeL Femur length. Maximum length of metafemur, measured from base to apex.

FWL* Forewing length. Length of forewing, measured from tegula to distal tip.

HaL Hair length. Length of the longest standing hair on first gastral tergite, measured from base to apex.

HL Head length. Maximum length of head in full-face view, excluding mandibles, measured from anteriormost point of clypeus to posterior-most point of head vertex, parallel to midline.

HS Head size. (HW + HL) / 2.

HW Head width. Maximum width of head in full-face view (including eyes if protruding; only in gynes).

ML Mesosoma length. Measured laterally from anterior surface of pronotum proper (excluding collar) to posterior extension of propodeal lobes.

MSW* Mesoscutum width. Maximum diameter of mesoscutum, measured dorsally.

NH Node height. Height of petiolar node, measured laterally, from the intersection point of the axes of maximum height and length to dorsal apex

OcD* Ocellar distance. Minimum distance between lateral ocelli, measured between median borders.

OcW* Ocellus width. Maximum diameter of median ocellus.

OED* Ocellar eye distance. Minimum distance between lateral ocellus and outer border of compound eye. 
PH Petiole height. Maximum height of petiole in lateral view, measured from ventral-most point of petiolar sternum to dorsal apex.

PL Petiole length. Maximum length of petiole in lateral view, measured from inflexion point of anterior constriction to posterior margin, perpendicular to axis of maximum height.

PS5 Length of maxillary palp segment $V$, measured from base to apex.

PS6 Length of maxillary palp segment VI, measured from base to apex.

SL Scape length. Maximum length of antennal scape in dorsal view excluding basal neck and condyle.

SW Scape width. Maximum width of antennal scape, measured dorsally.

TL Total length. The added lengths of head (excluding mandibles), mesosoma, petiole, and gaster.

2r* Maximum length of $2^{\text {nd }}$ radial crossvein (see Figs $5 \mathrm{e}, 6 \mathrm{~b}$ ).

$\mathbf{4 R s}+\mathbf{M}^{*}$ Length of $4^{\text {th }}$ radial sector fused with median (see Figs $5 \mathrm{e}, 6 \mathrm{~b}$ ).

CI Cephalic index. HW / HL $\times 100$

EI Eye Index. EL $/ \mathrm{HW} \times 100$

FeI Femur Index. FeL $/ \mathrm{HW} \times 100$

OI* Ocellar Index: OED / OcD × 100

PI Petiole Index. PH / PL $\times 100$

PSI Palp Segment Index. (PS5 + PS6) / HS $\times 100$

SI $\quad$ Scape index. SL $/ \mathrm{HW} \times 100$

SWI Scape width index. SW $/$ SL $\times 100$

WVI* Wing Vein Index. 4RsM / 2r × 100

Digital stacked images of most specimens (Figs 2-6) were acquired with a Leica DFC camera attached to a Leica MZ16 binocular microscope with Leica Application Suite v3 and stacked with Zerene-Stacker 64-bit. Images of labels were taken with a Nikon D60 camera with an AF-S Micro Nikkor $105 \mathrm{~mm}$ objective and an EM-140 DG macro ring flash. Photographs of genital structures of males (Figs 7, 10c-f) as well as of the male C. badia specimen (Fig. 10 a, b) were created with the help of Leica Application Suite v3.8, using a Leica DFC450 camera attached to a Leica Z16APO optics carrier. All images were processed with Adobe Photoshop 7.0.

\section{Material examined}

Type material of C. explodens: Holotype (minor worker): Brunei, Temburong, Kuala Belalong Field Studies Centre, 04³3'N, 11509'E, 60 m a.s.l., 10.XI.-5.XII.2015, leg. A. Laciny \& A. Kopchinskiy ("YG Vienna Colony", specimen number COCY 01565).

Paratypes $(59$ minor workers, 8 major workers, 16 gynes, and 6 males dry mounted; > 500 imagines stored in $96 \%$ ethanol): 19 minor workers, 2 major workers, 12 alate gynes, 4 dealate gynes, 6 males (including allotype) (all dry mounted), as well as 8 males, 2 alate gynes, ca. 500 minor workers (in alcohol) from the same nest sam- 
ple as holotype; 1 major worker, same locality and collector as holotype, 17.IV.2015, "YG 373 main natural nest"; 1 major worker, same data as holotype ("YG doorkeeper \#19"); 2 major workers, same data as holotype except 20.IV.2015, leg. A. Kopchinskiy ("cf. YG 39 (351) artificial nest"); 8 minor workers, 2 major workers, same locality as holotype, 2002, leg. D.W. Davidson ("YG KB02-108"); 4 minor workers, same locality and collector as previous, no collection date, "YG 2025"; 5 minor workers, same locality and collector as previous, I.2012, "YG T-trail (202)"; 5 minor workers, same locality and collector as previous, 15.V.2014, "YG-2 (73)"; 7 minor workers, same locality and collector as previous, 15.V.2014, "YG-2 (49)"; 2 minor workers, same data as previous except Batu Apoi Forest Reserve, N04³2', E115¹0', 200 m a.s.l., 25.XI.2004, ("CAYG A-370"); 15 minor workers (on 5 pins), same data as previous, except N045 5', E11519', 60 m, 3.VII.2002, ("YG KB02-108 voucher"); 4 minor workers, Thailand, Chumphon Province, Krom Luang Chumphon W.S, 3.II.2002, leg. W. Jaitrong (“WJT02-TH-0116”); 5 minor workers, West Malaysia, Kelantan, 60 km NE Tanah Rata, Tanah Kerajaan, 1000 m a.s.l., 12.-30.IV2007, leg. P. Cechovský.

Additional material: 3 pupae (Suppl. material 5) and 6 myrmecophilous crickets (Camponophilus sp., det. S. Ingrisch), from the same nest sample as the holotype.

For unique identification numbers of all 90 dry mounted specimens (60 minor workers, 8 major workers, 16 gynes, and 6 males), as well as information on caste and colony affiliation, see Suppl. material 6 "measurements".

The holotype and a portion of the paratypes will be deposited at the Brunei Museum; additional paratypes will be housed in the Universiti Brunei Darussalam, the Natural History Museum Vienna, the University of California (Davis, USA), the Natural History Museum of Los Angeles County (Los Angeles, USA), the Thailand Natural History Museum (Technopolis, Thailand), and the collection of H. Zettel (Vienna, Austria).

\section{Molecular results}

The topology of the phylogram based on the concatenated alignment of 2757 bp was concordant with topologies of COI and COII and not contradicted by the topology of cytB. The phylogram based on cad was statistically unresolved (data not shown). The obtained Bayesian consensus tree (Fig. 1) shows conspecificity of the newly obtained C. explodens sp. n. specimens from Brunei and Thailand (TUCIM 6600) with a sequence previously deposited under "Colobopsis cylindrica s.l. YG". While there is some intraspecific variation within the analysed $C$. explodens sp. n. specimens, they form a clade distinctly separate from the closely related $C$. badia. The male of $C$. badia (TUCIM 6463) is clearly grouped with its conspecific workers from a nearby locality, thus confirming species identity. The herein examined representatives of the $C$. saundersi subclade, $C$. explodens sp. n., $C$. badia and the undescribed $C$. nrSA (see Laciny et al. 2017), are clearly distinct from other members of the COCY group (e.g., C. cylindrica) and selected outgroup taxa of Colobopsis and Camponotus. 


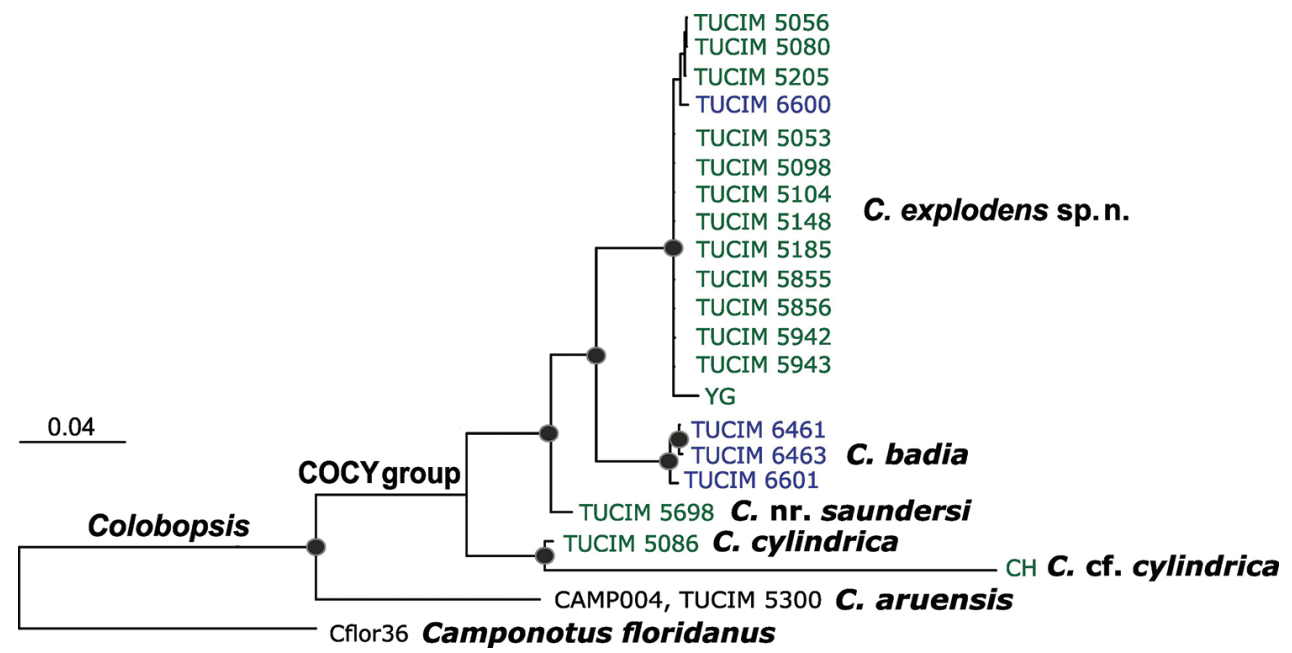

Figure I. Bayesian consensus phylogram of $C$. explodens sp. n. and related taxa based on the concatenated alignments (2757 bp) of the three mitochondrial (COI, COII, cytB) and one nuclear (cad) phylogenetic markers. Nodes with posterior probabilities above 0.94 are marked with black dots. Specimens from Borneo are shown in green, from Thailand in blue. TUCIM 6463 corresponds to a male specimen.

\section{Taxonomic results}

Colobopsis explodens Laciny \& Zettel, sp. n. http://zoobank.org/DB4767B0-C745-4843-BE3F-B17DBCEB3A96

Figs 2-9; Suppl. materials 1-7

Camponotus (Colobopsis) sp. Yellow Goo: Davidson et al. 2007: 470.

Camponotus (Colobopsis) sp. YG: Cook 2008. Davidson et al. 2012: 488.

Colobopsis sp. YG: Davidson et al. 2016: 518. Laciny et al. 2017: 95.

Etymology. Present participle of Latin explodere, referring to the "exploding"-like autothysis behaviour.

\section{Description of phenotypes.}

Minor worker (Figs 2, 4b-d; Suppl. material 1: S1a).

Measurements of holotype minor worker: TL 6.78; HW 1.48; HL 1.67; HS 1.58; PS5 0.23; PS6 0.25; EL 0.42; SL 1.33; SW 0.14; ML 2.05; HaL 0.15; PH 0.55; PL 0.47; NH 0.33; FeL 2.05. Indices: CI 88; SI 90; SWI 11; EI 29; PI 116; FeI 139; PSI 30.

Measurements of paratype minor workers: $(\mathrm{n}=59)$ : TL 4.74-7.21; HW 1.221.57; HL 1.30-1.78; HS 1.27-1.67; PS5 0.21-0.25 (20); PS6 0.20-0.26 (21); EL 0.33-0.43; SL 1.21-1.39; SW 0.11-0.16; ML 1.50-2.22; HaL 0.08-0.19; PH 0.410.56 (44); PL 0.33-0.49 (47); NH 0.24-0.38 (52); FeL 1.73-2.10. Indices: CI 85-94; SI 87-104; SWI 9-12; EI 27-29; PI 112-133 (41); FeI 123-151; PSI 28-35 (20).

Structures: Head (Fig. 2a) subovate, longer than wide, narrower anteriorly; sides posteriorly convex, posterior cephalic margin roundly convex; microstructure consisting of 


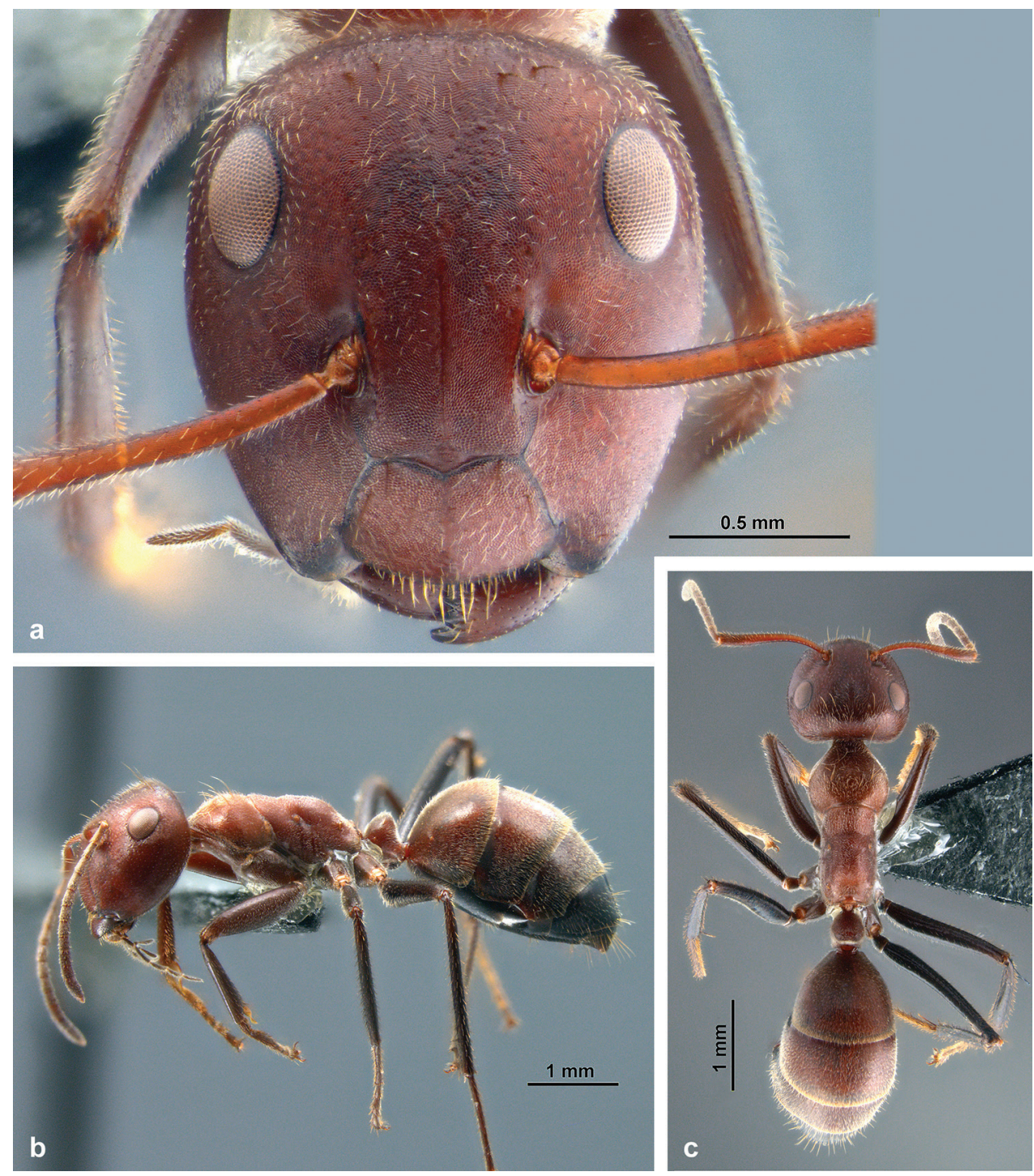

Figure 2. Habitus of C. explodens sp. n., holotype, minor worker; a full-face b lateral, and c dorsal view.

very fine, isodiametric or transverse mesh-like reticules; intermixed punctures very fine and inconspicuous on face, larger but shallow laterally and ventrally. Eyes small compared to other castes (EI 27-29, vs. 28-31 in major workers and 35-37 in gynes), flat, positioned dorsolaterally. Ocelli lacking, in some larger specimens position of median ocellus indicated by shallow impression. Frons with very fine impressed midline; frontal carinae slightly converging anteriorly, not elevated. Median carina of clypeus not reaching anterior clypeal margin, especially in small specimens. Mandibles mostly smooth, with rather dense punctures; masticatory margin with five teeth. Maxillary palpi long (PSI 28-35). Antennal scape long, its length roughly equal to head width (SI 87-104), moderately 

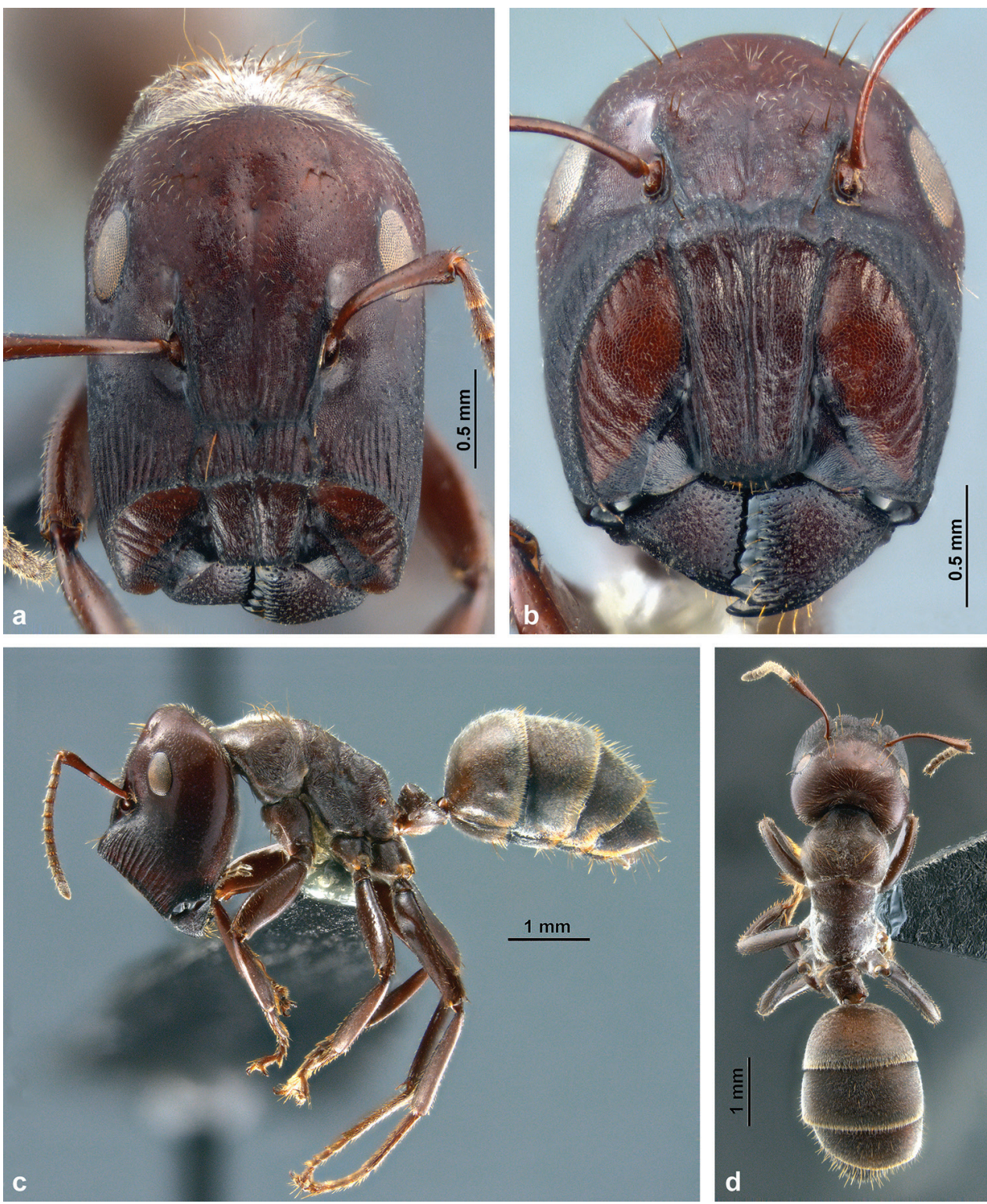

Figure 3. Habitus of C. explodens sp. n., paratype, major worker; a full-face view $\mathbf{b}$ frontal shield $\mathbf{c}$ lateral, and $\mathbf{d}$ dorsal view.

flattened, slightly widened towards apex, integument punctate. Antenna 12-segmented; antennal segment III approx. 1/5 shorter than each IV and V, and approx. 2/5 shorter than II. Mesosoma slender, moderately low. Microreticulation isodiametric or slightly transverse, dorsally denser than laterally. Metanotal region delimited from mesonotum by a shallow groove; groove delimiting metanotum from propodeum indistinct or missing. Dorsal and posterior outline of propodeum rounded in lateral view, or meeting at 
an obtuse angle, dorsal face slightly convex, posterior face flat to shallowly concave. Legs slender. Petiole with isodiametric reticulation; petiolar node moderately high, its short, slightly convex anterior and its rather straight posterior face forming a triangular shape in lateral view, its apex not truncated, rather rounded; node narrow in dorsal view, a crest indistinct; a medial depression indicated in most specimens. Gaster: dorsum of tergites I-III with extremely fine, dense, transverse microreticulation, slightly shiny (Fig. 4b); mesh-like reticulation wider on lateral areas of tergites I-III , tergite IV, and sternites , therefore meshes appearing not so strongly transverse, and the integument shinier (Fig. 4c). Exposed parts of tergite $\mathrm{V}$ and sternite $\mathrm{V}$ with dense, almost isodiametric reticulation, dull; base of tergite V (usually covered by tergite IV) sculptured as tergite IV.

Colour: Body mainly reddish brown. Vertex of head, margins of clypeus, masticatory and lateral margins of mandibles, dorsum and ventral margins of mesosoma, mid portion of gastral tergites I-III, and legs slightly darker brown in most specimens; some specimens with darker area extending medially from head vertex to frons. Gastral tergites and sternites with very narrow hyaline margins. All gastral sternites, lateral fourths and posterior margins of tergites I-III, as well as entire tergites IV and V black.

Pilosity: Dorsum of head with very short, inconspicuous, appressed and subdecumbent setae; a few very long, standing setae on frons near declivity to vertex, medial of frontal carinae, and on lateral portions of clypeus. Mesosoma and petiole with fine and short, whitish, velvety pilosity; long, standing, slightly undulated setae restricted to pronotum; declivity of propodeum and node of petiole with few very short standing setae. Gastral tergites with moderately dense, short whitish, decumbent setae and few slightly darker, longer standing setae, most of them in transverse rows near hind margins. Longest setae in transverse rows near hind margins of sternites and at base of gastral tergite $\mathrm{V}$.

Notes: Minor workers of Colobopsis explodens sp. n. show a continuous size variation across a remarkably wide range, similar to that found in the undescribed Colobopsis sp. nrSA (Fig. 8; compare with Laciny et al. 2017).

Phragmotic major worker (Figs 3, 4a; Suppl. material 1: S1b).

Measurements of paratype major workers ( $\mathrm{n}=8)$ : TL 7.30-8.71; HW 1.72-1.89; HL 2.25-2.58; HS 1.99-2.20; PS5 0.15-0.17 (6); PS6 0.15-0.17 (6); EL 0.50-0.56; SL 1.15-1.26; SW 0.17-0.20; ML 2.22-2.74; HaL 0.11-0.20; PH 0.59-0.69 (6); PL 0.45-0.51 (6); NH 0.40-0.45 (6); FeL 1.50-1.70. Indices: CI 71-77; SI 64-69; SWI 14-17; EI 28-31; PI 125-143 (6); FeI 87-95; PSI 14-17 (6).

Structures: Integument mostly dull, only head and legs shiny. Head (Fig. 3a) large, subcylindrical, anteriorly truncated. On posterior areas of face punctation slightly stronger than in minor worker. Eyes somewhat larger and more distant from vertex compared to minor worker. Ocelli lacking, their positions often indicated by shallow grooves (Fig. 4a). Anterior part of head forming a large shield (Fig. 3a, b) formed by clypeal and genal components, limited by a sharp and elevated crest so that the shield surface appears concave in lateral view. Shield with fine isodiametric reticulation and rather variable, mostly longitudinal rugae; most prominent are a pair of rugae along sides of clypeus and a single median carina that does not reach the anterior margin, 

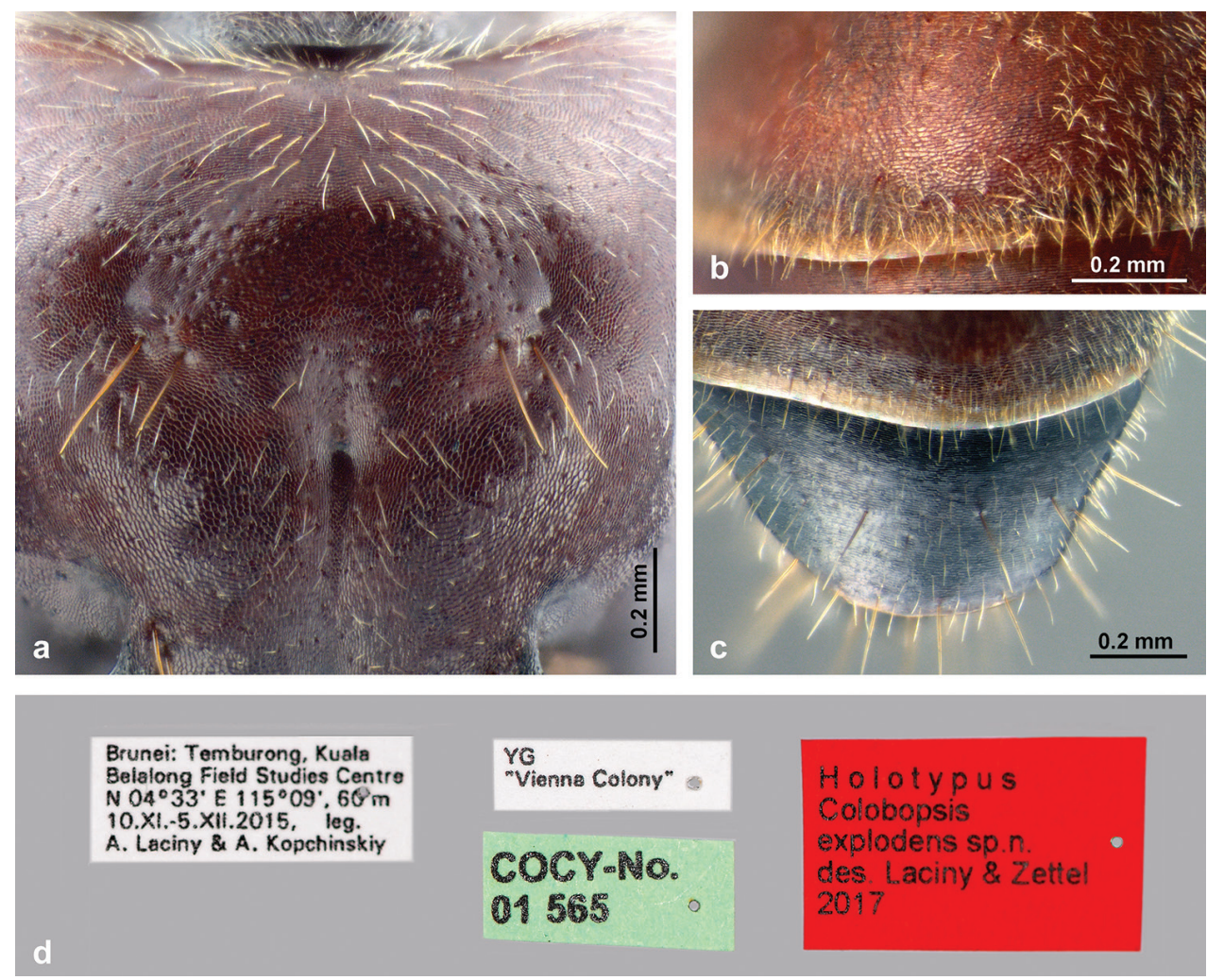

Figure 4. Cuticular microsculpture of C. explodens sp. n.; a vertex of major worker (paratype) b gastral tergite I, and c gastral tergite IV of minor worker (holotype) $\mathbf{d}$ labels of holotype, minor worker.

often reduced towards base. Genal part with curved rugae of variable number, length, and distinctiveness, but only exceptionally reaching onto the anteromedial triangle. Additional longitudinal rugae on clypeus often present, including a usually distinct pair of paramedian rugae running from base of clypeus over the crest anteriorly towards middle of shield; in specimens with short median carina, the area between these carinae more or less grooved. Longitudinal striation more regular and pronounced on frons and genae up to level of antennal insertions, laterally on genae similarly long and strong. Mandible with sharp and high ventrolateral ridge, coarsely punctate, its lateral face weakly rugose-striate; masticatory margin with acute apex and few (1-3) more or less distinct, very blunt teeth in distal half (Fig. 3b). Maxillary palpi very short (PSI 14-16). Antenna considerably shorter than head width (SI 64-69) and stouter than in all other morphs (Figs 3a, 8b); antennal scape distinctly widened towards apex. Mesosoma stouter and higher than in minors, especially promesonotum expanded; in lateral view dorsal and posterior face of propodeum forming an obtuse angle, somewhat less rounded than in minor workers, dorsally without concavity. Legs much shorter and stouter than in minors (Fig. 3c). Shape of petiole similar to minor workers, somewhat wider in dorsal view. Structures of gaster similar as in minor worker. 
Colour: Overall slightly darker than minor worker; head, legs and mesosoma reddish brown; gaster slightly darker chocolate-brown, becoming darker towards caudal apex, hyaline margins yellowish; elevated crest of frontal shield, anterior clypeal margin, frontal carinae, and masticatory and lateral margin of mandibles blackish brown.

Pilosity: As in minor worker, except long setae on clypeus sides restricted to the area behind clypeal shield; mesonotum with standing setae which are approx. half the length of those on pronotum.

Notes: The head shield with a sharp, elevated crest is typical for majors of the Colobopsis saundersi complex (Fig. 3b).

Gyne (Fig. 5, Suppl. material 3: S3d).

Measurements of paratype gynes $(\mathrm{n}=16)$ : TL 10.50-12.16; HW 1.74-1.83; HL 2.28-2.45; HS 2.02-2.14; PS5 0.19-0.21 (13); PS6 0.19-0.23 (13); EL 0.62-0.66; SL 1.33-1.45; SW 0.20-0.22; ML 4.11-4.63; HaL 0.14-0.29 (15); PH 0.77-0.92 (11); PL 0.54-0.67 (10); NH 0.40-0.54 (11); FeL 2.25-2.35; OcW 0.13-0.16; OED 0.34-0.38; OcD 0.54-0.64; FWL 9.72-10.50 (11); MSW 1.68-2.15; 2r 0.50-0.64 (12); 4Rs+M 0.14-0.32 (12). Indices: CI 73-77; SI 75-80; SWI 15-16; EI 35-37; PI 123-150 (8); FeI 125-132; PSI 18-20 (13); OI 54-69; WVI 26-58 (12).

Structures: Head (Fig. 5a) large, subcylindrical, anteriorly truncated, similar to that in major worker with the following exceptions: eyes larger than in workers (EI 35-37) and breaking outline of head in full-face view. Ocelli fully developed, their colour ranging from almost clear to reddish amber. Head shield sharply delimited, but slightly smaller than in major worker, distinctly narrower than head width. Striation of clypeus, frons, and genae similar as in major, though somewhat more strongly developed on lateral parts of shield. Mandible with sharp ventrolateral ridge; its lateral face weakly rugose-striate, narrower than in major; dorsal-anterior face punctured; masticatory margin with acute apex and 3-4 blunt teeth in distal half, mandible basally with blunt ridges (Fig. 5b). Maxillary palpi moderately long (PSI 18-20). Antennal scape moderately long, slightly shorter than head width (SI 75-80), somewhat widened towards apex (Figs 5a, 8b). Mesosoma large, structures as typical for caste; propodeum large and evenly convex in lateral view. Cuticular microstructures dorsally consisting of very fine punctation, with intermixed larger punctures, laterally finely reticulated. Legs stout, but not as short as in major (Fig. 5c). Forewing venation strongly reduced, as in most Camponotini; M-Cu absent; Mf2+ interstitial (Fig. 5e). Petiole distinctly wider than in workers; node more rounded in lateral view, in some specimens its apex shallowly impressed medially, in others with two shallow lateral impressions forming a trilobed outline. Gastral tergites I-IV and sternites I-IV with extremely fine and dense microstructures consisting of strongly transverse meshes; only sides of tergites with wide mesh-like reticulation and shiny; tergite $\mathrm{V}$ with dense isodiametric reticulation.

Colour: Chiefly as in major worker. Head and pronotum reddish brown; ventral and posterior mesosoma, petiole, legs and gaster somewhat darker chocolate-brown; mandibles and ridges of clypeal shield blackish brown. Pronotum and mesonotum with very narrow yellow margins. Gastral tergites medially with very narrow hyaline margins; sternites with relatively broad posterior margins. Wings hyaline, but forewing 

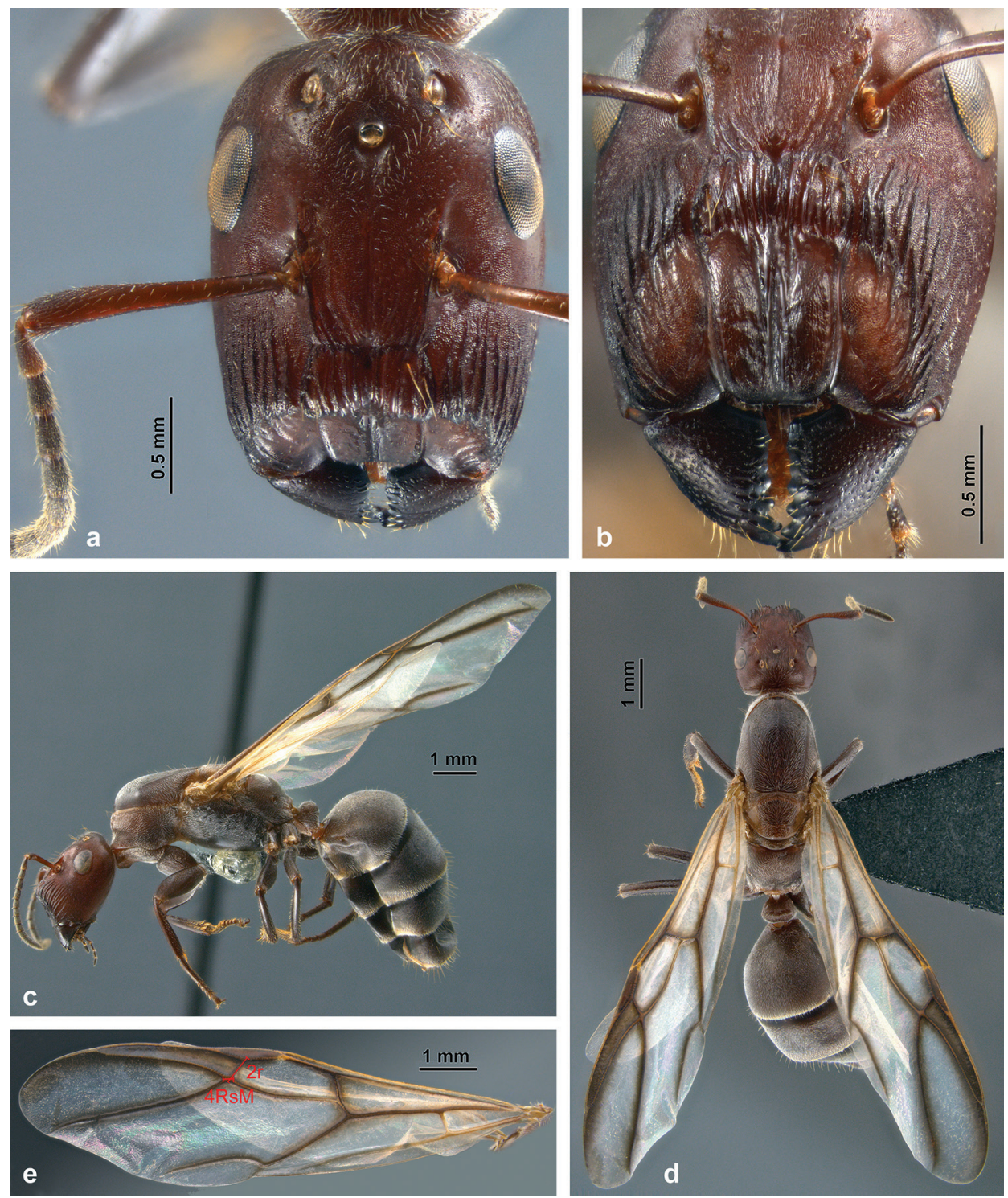

Figure 5. Habitus of C. explodens sp. n., paratype, alate gyne; a full-face view $\mathbf{b}$ frontal shield $\mathbf{c}$ lateral $\mathbf{d}$ dorsal view $\mathbf{e}$ forewing with indicated measurements $2 \mathrm{r}$ and $4 \mathrm{Rs} \mathrm{M}$.

cells along veins, as well as pterostigma darkened to brownish. On hind wing all veins pale yellow (Fig. 5c-e).

Pilosity: Short pilosity and distribution of long setae on head, petiole, and gaster similar as in major worker, but that of mesosoma different; pronotum with few long, undulated setae. Medial part of mesonotum (between parapsidal furrows) with numerous long erect setae, scutellum with few long erect setae; lateral part of mesonotum in front of tegulae without setae. 
Notes: The head shield with a sharp, elevated crest is typical for gynes of the Colobopsis saundersi complex (Fig. 5b).

Male (Figs 6,7). This is the first detailed description and illustration of males from the C. cylindrica group.

Measurements of allotype male: TL 7.11; HW 1.26; HL 1.20; HS 1.23; PS5 0.20; PS6 0.15; EL 0.44; SL 0.84; SW 0.11; ML 2.54; HaL n.a.; PH 0.46; PL.40; NH 0.29; FeL 1.83; OcW 0.18; OED 0.27; OcD 0.43; FWL 6.33; MSW 1.37; 2r 0.38; 4Rs+M 0.27. Indices: CI 105; SI 66; SWI 13; EI 35; PI 116; FeI 145; PSI 28; OI 62; WVI 70.

Measurements of paratype males ( $\mathrm{n}=5$ ): TL 6.46-6.85; HW 1.24-1.29 (4); HL 1.14-1.24; HS 1.20-1.27; PS5 0.17-0.21 (4); PS6 0.13-0.17 (4); EL 0.43-0.46; SL 0.80-0.85; SW 0.10-0.12; ML 2.38-2.87; HaL n.a.; PH 0.45-0.49 (4); PL 0.380.40 (4); NH 0.26-0.33 (4); FeL 1.71-1.86; OcW 0.18-0.19; OED 0.25-0.27; OcD 0.43-0.46; FWL 5.87-6.33; MSW 1.17-1.50; 2r 0.38-0.47; 4Rs+M 0.14-0.22. Indices: CI 104-110 (4); SI 64-67 (4); SWI 12-15; EI 35-36 (4); PI 113-123 (4); FeI 136-151 (4); PSI 27-30 (4); OI 53-62; WVI 31-53.

Structures: Head (Fig. 6a) small, subtrapezoidal, eyes very large, round and protruding, EL more than one third of HL (EI 35-36). Ocelli very large, diameters larger than in gynes. Integument of head rather matt. Frons and genae finely reticulated, genae additionally finely punctured. Clypeus with some stronger punctures at margins (at base of setae), median carina weakly developed, present in proximal third of clypeus or entirely obsolete. Frons with impressed midline from median ocellus to level of antennal insertions. Frontal carinae weakly developed, converging more strongly than in minor worker. Mandible short with reduced dentition, masticatory margin with 2-3 blunt teeth; dorsal surface finely punctate. Maxillary palpi long (PSI 27-30). Antenna 13-segmented; scapes short (SI 64-67) and relatively slender (Fig. 8b). First funicular segment conspicuously enlarged distally, pear-shaped, 30-50\% wider and ca. 20\% longer than the following segment (Fig. 6a); all other funicular segments cylindrical, without modifications. Mesosoma large, structures as typical for alate ants. Mesoscutum anteriorly strongly convex with narrow impressed midline in posterior tenth. Scutellum moderately elevated; propodeum evenly convex. Cuticular microstructures of mesosoma consisting of a very fine reticulation with intermixed minute punctures at bases of short hairs, additionally with larger punctures dorsally at bases of erect setae. Legs very long and slender (FeI 136-151). Forewing venation strongly reduced, as in most Camponotini. $\mathrm{M}-\mathrm{Cu}$ absent; $4 \mathrm{Rs}+\mathrm{M}$ shortly developed or (more rarely) Mf2+ interstitial (Fig. 6b). Petiole small; in lateral view node more bluntly rounded than in female castes, anterior and posterior faces straight, not convex, apex not impressed medially in dorsal view. Gastral tergites I-IV and sternites I-IV with fine and dense microreticulation consisting of moderately transverse meshes; only sides of tergites with wide meshes and shiny; tergite $\mathrm{V}$ with almost isodiametric reticulation. Sternite VI posteriorly emarginated, sternite VII truncated.

Genital structures (Fig. 7): Genital capsule (Fig. 7a-c) approx. as long as wide in dorsal aspect (Fig. 7a), ventrally longer than dorsally, protruding from apex of gaster. Gonopod high, distally broadly rounded. Gonostylus (Fig. 7c) elongated and acuminated, with reticulated microstructure (only visible at very high magnification) and 

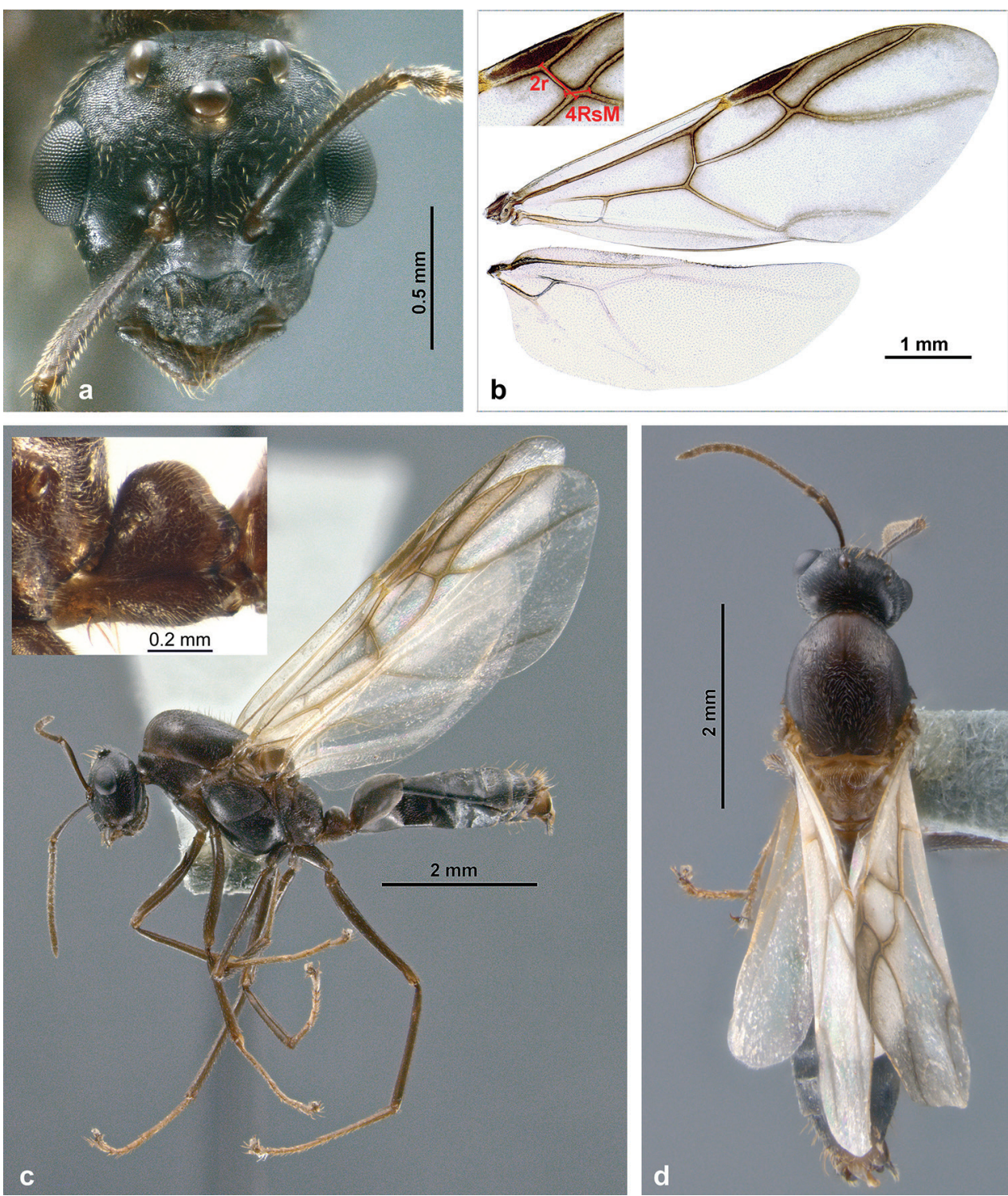

Figure 6. Habitus of $C$. explodens sp. n. allotype, male; $\mathbf{a}$ full-face view $\mathbf{b}$ wings (see insert for illustration of measurements $2 \mathrm{r}$ and $4 \mathrm{RsM}$ ) $\mathbf{c}$ lateral (see insert for detailed view of petiole), and $\mathbf{d}$ dorsal view.

some long setae. Basivolsella (Fig. 7e) dorsally with roundish structure, ventrally with evenly distributed, comparatively short setae. Digitus (Fig. 7e) large, evenly widened towards apex; apex rounded but with rectangular corner ventrally. Penis valvae (Fig. 7d) in dorsal aspect broad at base, but very narrow distally. Valviceps leaf-shaped in lateral view, apically rounded; surface smooth; ventral margin with very fine serration.

Colour: Mainly dark chocolate-brown. Head somewhat darker; eyes pale grey to blackish; ocelli translucent, ranging from almost clear to reddish amber. Antennae 

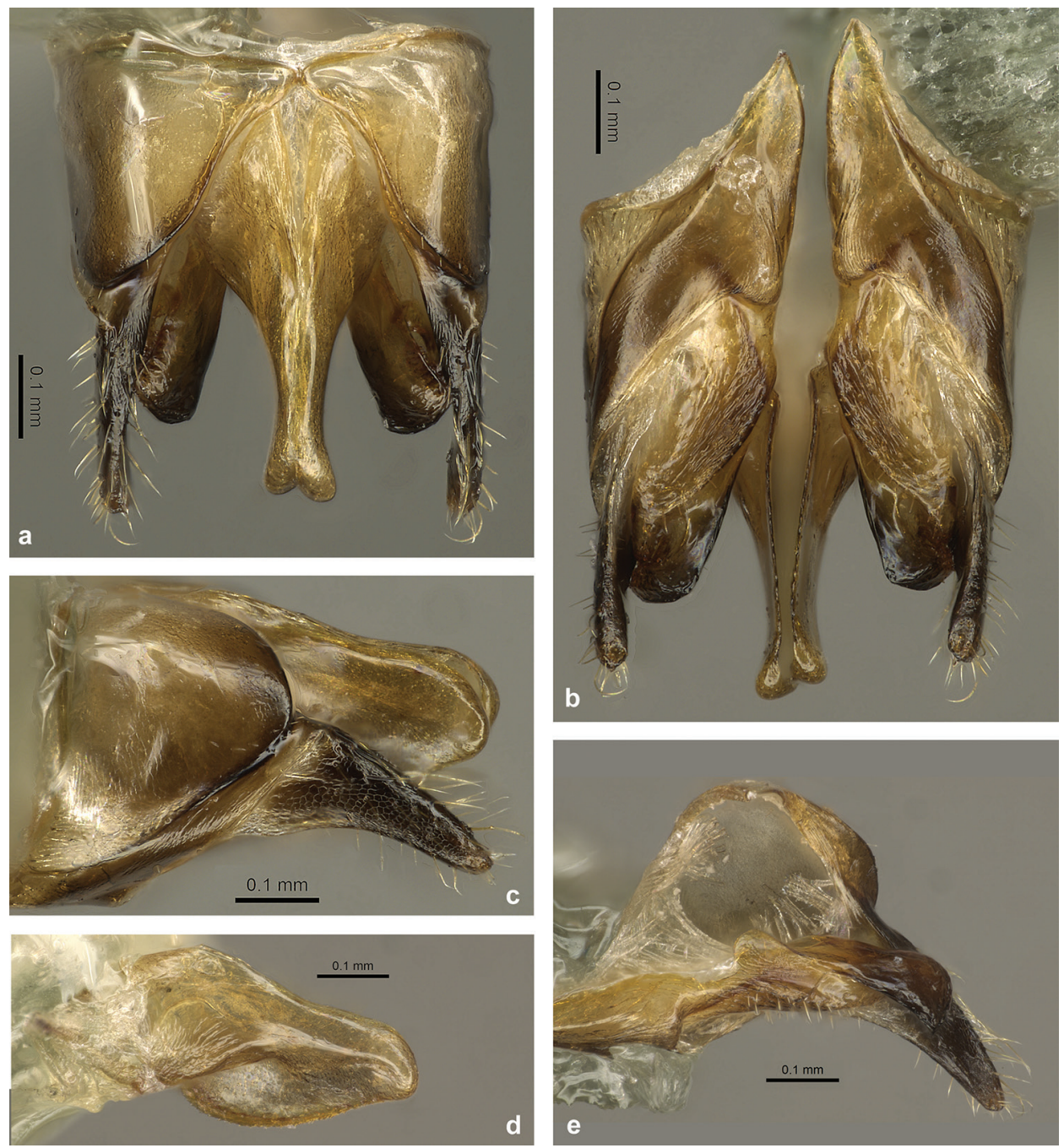

Figure 7. Genital structures of $C$. explodens sp. n. paratype, male; genital capsule in a dorsal $\mathbf{b}$ ventral, and $\mathbf{c}$ lateral view $\mathbf{d}$ left penis valve $\mathbf{e}$ right volsella and gonostylus.

and legs lighter brown, fading into yellowish towards apices. Margins of mesoscutum, scutellum, and metanotum lighter yellowish brown. Gastral tergites medially with very narrow hyaline margins; sternites with relatively broad, indistinctly separated posterior margins. Wings almost hyaline, with a slight whitish tinge, but forewing cells along veins, as well as pterostigma darkened to brownish, all veins pale yellowish brown. On hind wing all veins pale yellow.

Pilosity: On head setae sparsely distributed, short, inconspicuous, appressed, subdecumbent; a few very long standing setae on frons near vertex, and on anterior and posterior clypeal margins. Mandibles with dense short pilosity on lateral face, and few moderately long setae on anterolateral margin. Short pilosity and distribution of long 


\section{Femur Index}

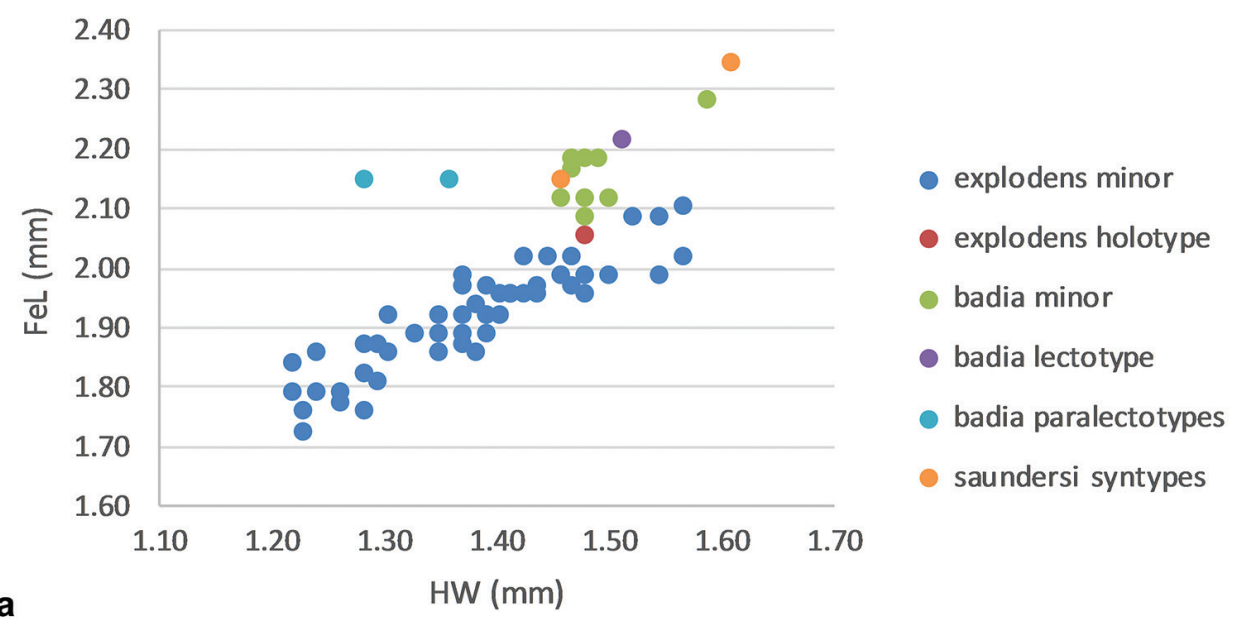

\section{Scape Index}

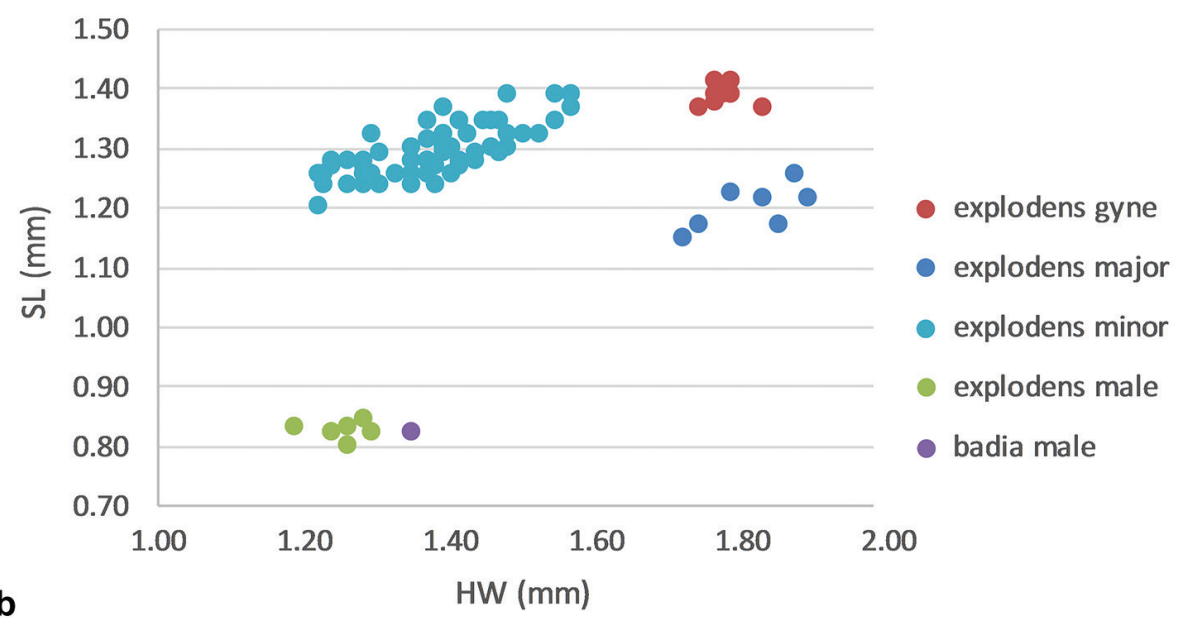

Figure 8. Variation of relevant morphometric measurements for the distinction of castes and species; a Metafemur length $(\mathrm{FeL})$ in relation to head width (HW) for minor workers of $C$. explodens sp. n., as well as minor workers of $C$. badia and C. saundersi (type specimens plotted separately) b Scape length (SL) in relation to head width (HW) for minor workers, major workers, gynes and males of $C$. explodens sp. n., as well as male of $C$. badia.

setae on mesosoma, petiole, and gaster similar as in gyne, but pronotum lacking long, undulated setae. Medial part of mesonotum (between parapsidal furrows) with numerous long erect setae, scutellum with few long erect setae; lateral part of mesonotum in front of tegulae without setae. Tegulae with dense brush of setae. Petiole with a few stout setae anteroventrally (see insert Fig. 6c). Petiolar node lacking any standing setae; 
gastral tergite I without or with few subdecumbent, moderately long setae. Posterior gastral tergites and sternites (segments II and following) with sparse, relatively long, obliquely standing setae.

\section{Biological notes on Colobopsis explodens sp. $\mathrm{n}$.}

Colonies of C. explodens sp. n. observed in the Ulu Temburong National Park are commonly polydomous and polygynous. This species was selected as a model for the study of the "exploding ants" because among the species with advanced autothysis behaviour it was the most abundant COCY taxon in the vicinity of KBFSC.

Colobopsis explodens sp. n. frequently nests on dipterocarp trees and its colonies can contain thousands of individuals. The largest part of the studied colony lived on a $60 \mathrm{~m}$ tall Shorea johorensis Sym. (Dipterocarpaceae) tree identified morphologically and by DNA barcoding (matK, identical to GenBank accession number KY973022, E-value is zero; Heckenhauer et al. 2017). The colony's foraging ground included the canopy of the main tree, its direct vicinity, and also covered canopies of a $25 \mathrm{~m}$ tall Horsfieldia wallichii (Hook.f. \& Th.) Warb. (Myristicaceae) tree and a smaller tree of Shorea maxwelliana King $(9 \mathrm{~m})$. Colony fragments on all trees were connected by ant trails either through the canopy or on the forest floor in the litter layer. The total area occupied by the colony was estimated to be at least $2500 \mathrm{~m}^{2}$.

The colonies are distributed three-dimensionally, occupying any suitable nesting ground within the colony boundaries. On the main tree, we found four nesting sites of the examined colony in dead branches at heights ranging between 35 and $55 \mathrm{~m}$ above ground and two nesting sites in the living stem 50-60 m above ground. No nests in living branches were observed. At least five nest entrances were also seen in the stem of $S$. maxwelliana. No signs of necrosis of the plant tissue were observed around stem entrances.

The translocation of a nest fragment in a fallen branch to the laboratory's terrace, $30 \mathrm{~m}$ away from its original location, resulted in the expansion of the colony's foraging ground to a neighbouring Shorea sp. tree where these ants were not previously present, while the connection to the colony on the original host tree was maintained.

If provided with an appropriate artificial nest (Fig. 9c-d), C. explodens sp. n. ants will inhabit it within several weeks up to several months and even use it to rear brood. One artificial nest, mounted on the main host tree, was colonized one week after it was installed. For the activity assessment, the easily accessible artificial nest \#38 was observed. During behavioural monitoring, C. explodens sp. n. was observed to be mainly diurnal, foraging between 6:00 and 18:00 hrs, with peak activity around 9:00 and 16:00 hrs (Fig. 9a). The activity correlated positively with the temperature with lowest values at $24.2{ }^{\circ} \mathrm{C}$ and highest at $28.6{ }^{\circ} \mathrm{C}$ (Fig. 9b). The atmospheric pressure and clouds did not influence the activity of $C$. explodens sp. n. (Suppl. material 6 "activity"); humidity was constant over the period of observations ranging from 86 to $88 \%$. A slight rain on a warm day did not reduce the activity of ants near the nest but no activity was observed during heavy rains. However, if a shelter was provided, C. explodens sp. n. remained active 

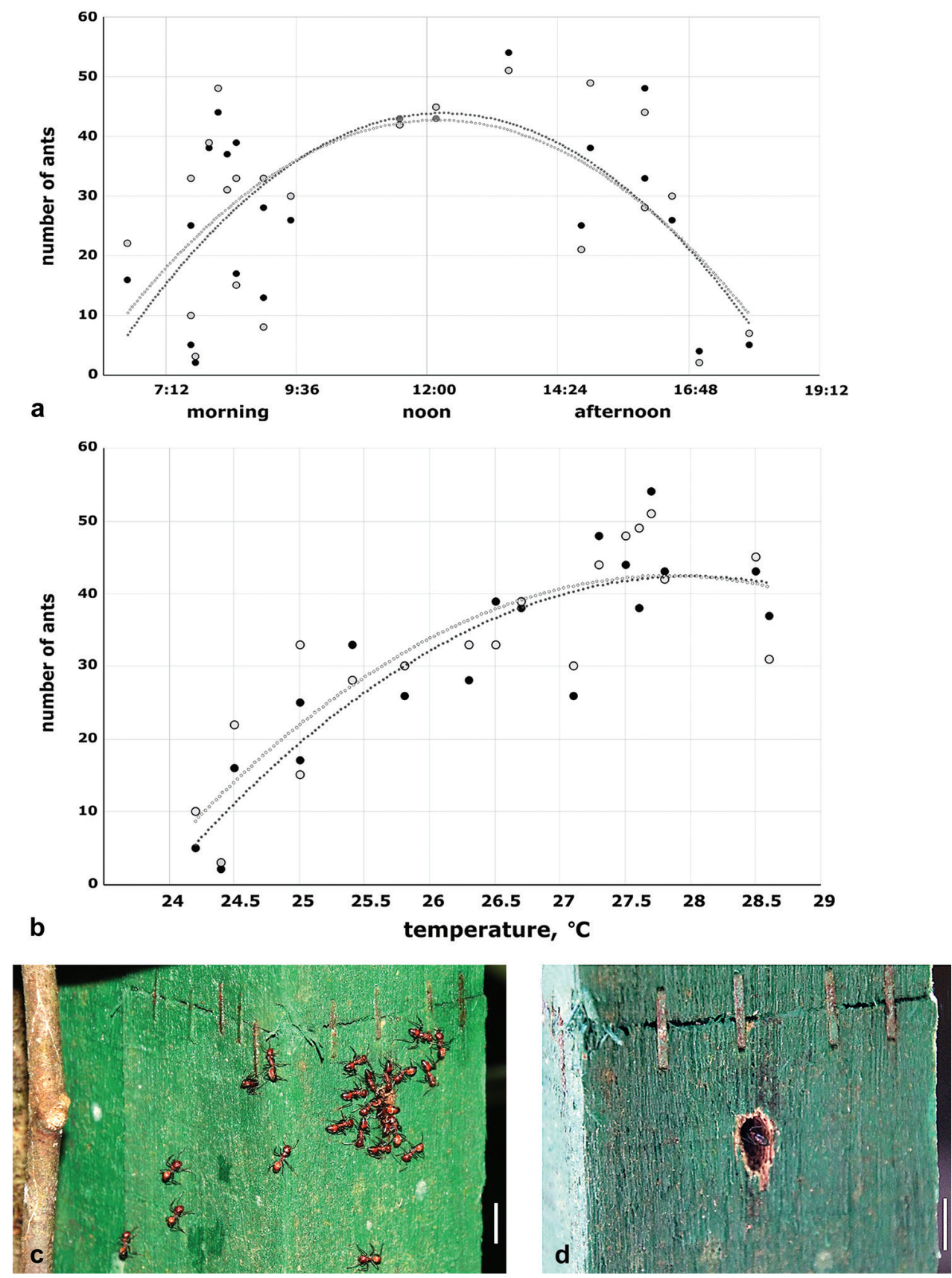

Figure 9. Activity of C. explodens sp. n. at the entrance to the artificial nest \#38. a Scatter plot of the number of minor workers entering (black dots) and leaving (open dots) the nest depending on the time of day $\mathbf{b}$ Scatter plot of the number of minor worker ants entering (black dots) and leaving (open dots) the nest depending on the air temperature. Polynomial trend lines on $a$ and $b$ are shown for the numbers of entering (black) and exiting (grey) minor workers $\mathbf{c}$ and $\mathbf{d}$ show high and low worker activity near the entrance of nest \#38, respectively; white bars denote $1 \mathrm{~cm}$. 
also during the rain and even after sunset. A drastic reduction in the number of minor workers at the nest entrance was observed on the days of nuptial flight, when several alate gynes and males left the nest in the early evening (Suppl. material 6 "activity"). Between one and six minor workers ("guards") were frequently positioned at the nest entrance, touching all incoming and outgoing workers with their antennae and seemingly monitoring the activity of foragers. In the early afternoon of the day with the highest activity, larvae were carried out of the nest. No carrying of larvae into the nest was ever observed.

Remarkably, during all observations the numbers of the minor workers leaving and entering the nest were almost equal. The fact that this proportion did not change over the day (Fig. 9a) suggests a tendency to maintain a constant number of individuals present inside the nest.

After dusk, other species of Camponotini such as Polyrhachis spp., Camponotus spp., and Dinomyrmex gigas (Latreille, 1802) were observed on the trees in the vicinity of the artificial nest.

Within the colonies, minor workers were by far the most abundant caste of $C$. explodens sp. n., whereas major workers (soldiers) were rare and almost never seen outside the nest. Alate gynes and males were observed leaving the nest during nuptial flight after dusk on two occasions during our field observations (Suppl. material 6 "activity"). Several more alate sexuals were found inside a detached nest fragment (Suppl. material 3). The same nest fragment also contained symbiotic ant crickets of the genus Camponophilus Ingrisch, 1995. DNA barcoding of the cricket based on COI sequence resulted in the highest value of $80 \%$ similarity to COI sequences of insects from several groups including Mann's ant cricket Myrmecophilus manni (Schimmer, 1911) (EU938370, Fenn et al. 2008). Thus, the molecular identification of these crickets is currently not possible due to lack of reference sequences.

Observations have shown that minor workers of $C$. explodens sp. n. display a characteristic, possibly defensive pose with raised gaster (Suppl. material 1: S1a) (compare with Davidson et al. 2007) and are extremely prone to self-sacrifice when threatened. The mandibular gland content is released during autothysis by contracting the gaster until the integument ruptures, leading to the death of the ant (Suppl. material 4). The secretion is slightly viscous, sticky, and has a species-specific bright yellow colour and a distinctive spice-like odour (Hoenigsberger et al., in prep.).

Minor workers of $C$. explodens sp. n. spend significant time on leaves, which has previously been hypothesized to contribute to their nutrition (compare with Davidson et al. 2007, 2016). However, the exact purpose of their activity on leaves is yet to be understood. Observations suggest a patrolling or monitoring behaviour aiming at the removal of debris from the phyllosphere (mainly adaxial leaf surface but also abaxial leaf and petiole surfaces) and possible deterrence of intruding arthropods. Similar "cleaning" behaviour was observed in vitro, as well.

Another very specific behaviour was exhibited on the tree bark: Minor workers "graze" on the layers of epiphytes (mosses, lichens, algae, filamentous fungi, and yeasts) with their mandibles, often for up to 60 minutes. This behaviour differs from the cleaning behaviour on leaves and presumably contributes to the ants' nutrition. 
Preliminary feeding experiments using cultures of filamentous fungi isolated from the phyllosphere of the host trees remained unsuccessful, no fungal feeding was observed. Only a suspension of yeast in water was accepted in vitro (M. Rahimi, pers. obs.). However, minor workers of C. explodens sp. n. have been observed to feed on small dead insects, fruit, and fish when offered on the foraging grounds (A. Kopchinskiy, A. Laciny \& M. Hoenigsberger pers. obs.).

Commonly observed modes of behaviour of $C$. explodens sp. n. in situ and in vitro as well as a variety of nesting sites are documented in the Suppl. material 7 (Video S7).

The molecular analysis of the mandibular gland (MG) content of C. explodens sp. n. resulted in PCR amplification and sequencing of the 16S rRNA fragment of the bacteria Blochmannia sp. (Gammaproteobacteria), a genus of obligate symbiotic bacteria found in carpenter ants (Williams and Wernegreen 2015). We revealed four identical mOTUs originating from two different DNA extracts from samples composed of five pooled MG reservoirs of the minor workers each. The sequences of 728 nt were $99 \%$ similar (11 SNP sites) to the "uncultured bacterium clone 193-11" KC136854 from Camponotus sp. voucher KC-A017-01 defined as Blochmannia sp. in Russell et al. (2012).

More detailed data on autothysis, composition of mandibular gland secretion, biodiversity of the COCY-associated microorganisms, and experimental assessment of nutrition will be presented in future publications.

\section{Colobopsis badia (Smith, 1857)}

Figs 8,10

Formica badia: Smith 1857: 54.

Camponotus badius: Roger 1863: 3 .

Colobopsis badia: Ward et al. 2016: 350. Bolton 2017.

Type material examined. 1 lectotype minor worker (Oxford University Museum of Natural History, present designation), Singapore, "Formica badia", "Syntype", CASENT 0901897, "Lectotypus Formica badia Smith, 1857 des. Laciny \& Zettel, 2017", 2 paralectotype minor workers (Oxford University Museum of Natural History) mounted on the same card, Sarawak ("Sar 32"), "Formica badia", "Syntype", "Paralectotypes Formica badia Smith, 1857".

Additional material examined. 1 male (Natural History Museum Vienna), Thailand, Trang Province, Nayong District, Khao Chong Botanical Garden, at light of head quarter, $7^{\circ} 33^{\prime} \mathrm{N}, 99^{\circ} 46^{\prime} \mathrm{E}, 60 \mathrm{~m}$ a.s.l., 1-7.VI.2016, leg. H. Zettel (68); $10 \mathrm{mi}-$ nor workers (Natural History Museum Vienna), Thailand, Trang Province, Nayong District, Khao Chong Botanical Garden, trail to Ton Pliw Waterfall, N07'32'34", E9947'33", 150 m a.s.l., 1-7.VI.2016, leg. H. Zettel (66-4).

Description notes on the type specimens. Lectotype: Minor worker glued to a square cardboard, in relatively good condition; right hind leg missing; tarsi of middle 

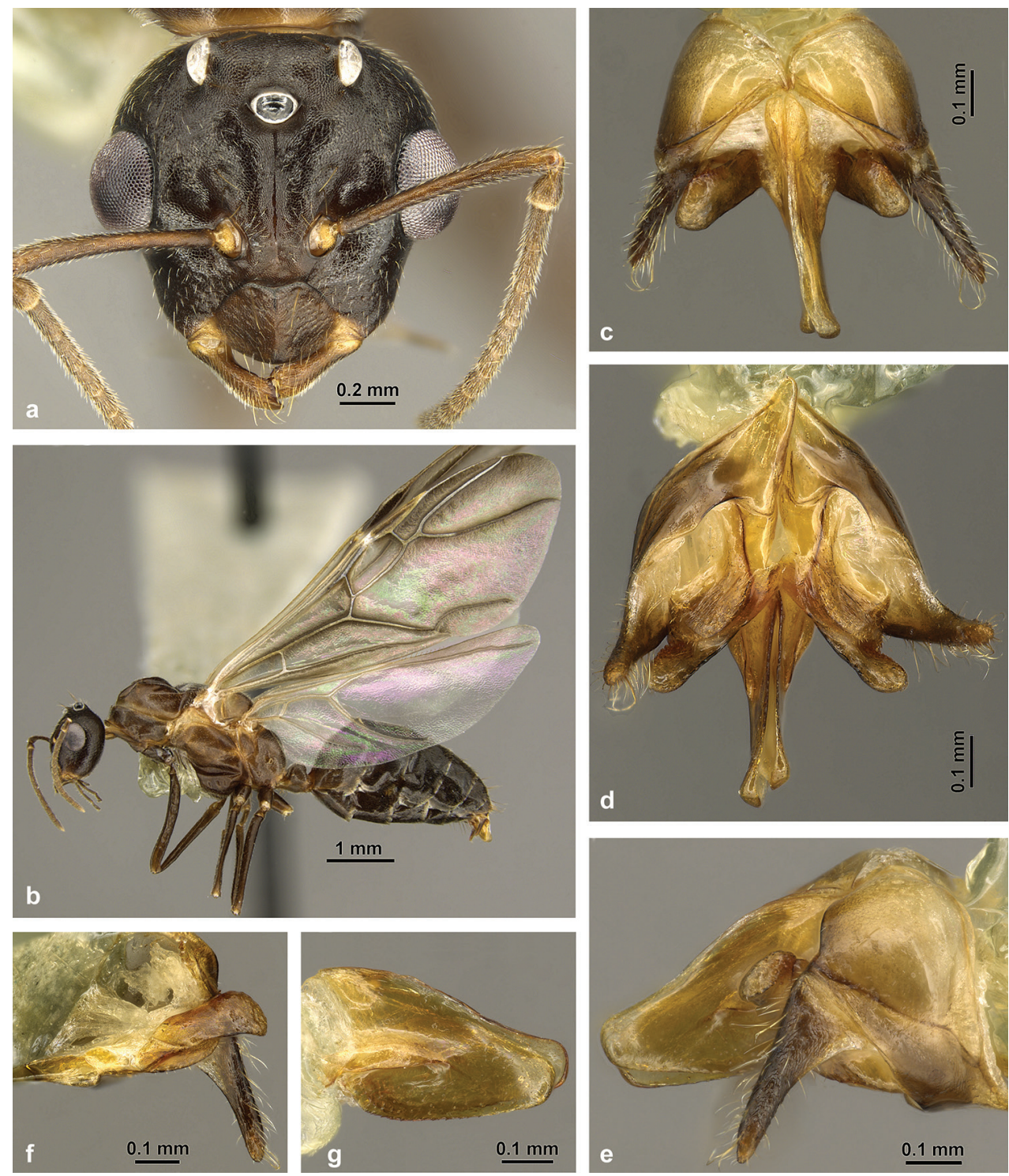

Figure I 0. Habitus of C. badia, male; a frontal b lateral; genital capsule in c dorsal d ventral, and e lateral view $\mathbf{f}$ right volsella and gonostylus $\mathbf{g}$ left penis valve.

legs and left hind leg broken; erect setae on dorsum probably lost. Structures agree well with other species of the $C$. saundersi complex, a few characteristic features are given: Setae on scape more decumbent than in C. explodens sp. n. Dorsal outline of mesosoma almost straight, only with weak indentation at meso-metanotal suture. Propodeum forming a distinct obtuse angle in lateral view. Petiolar node relatively short, apex acute in lateral view, its crest slightly indented in middle. Tergites I-III with very fine, strongly transverse microsculpture (lateral parts not visible). Colour relative- 
ly dark brown; appendages strongly infuscate; antennal segments III-XII, meso- and metafemora almost black.

Paralectotypes: Two minor workers glued to the same square cardboard, in relatively poor condition. Left specimen with damaged head and gaster, lacking right middle leg; major parts of body covered by dirt or glue; most erect setae probably lost. Right specimen with slightly damaged head, lacking gaster and right hind leg; some parts of body covered by dirt or glue; most erect setae probably lost. The two specimens are probably conspecific, but conspecificity with the lectotype is uncertain. The combination of morphological features is intermediate between $C$. badia and $C$. explodens sp. n.: setae on scape similar to $C$. explodens sp. n., more erect than in the lectotype; dorsal outline of mesosoma intermediate, more structured than in the lectotype, but propodeum with angle; shape of node intermediate, apex more acute than in C. explodens sp. n. Colour almost as dark as in the lectotype.

Measurements of lectotype minor worker: TL 6.13; HW 1.51; HL 1.63; HS 1.57; PS5 n.a.; PS6 n.a.; EL 0.40; SL 1.43; SW 0.15; ML 1.96; HaL 0.17; PH 0.54; PL 0.36; NH 0.32; FeL 2.22. Indices: CI 93; SI 95; SWI 10; EI 26; PI 150; FeI 147; PSI n.a.

Measurements of paralectotype minor workers* $(n=2)$ : TL 6.13, n.a.; HW n.a., 1.36; HL n.a., 1.52; HS n.a., 1.44; PS5 n.a., 0.21; PS6 n.a., 0.25; EL 0.36, 0.37; SL 1.39, 1.40; SW 0.12, 0.13; ML 1.89; HaL 0.13, n.a.; PH n.a., 0.51; PL 0.37, 0.42; NH 0.27; FeL 2.15. Indices: CI n.a., 89; SI n.a., 103; SWI 8, 9; EI n.a., 27; PI n.a., 121; FeI n.a., 158; PSI n.a., 32. *One specimen with strongly damaged head, one with missing gaster.

Measurements of non-type minor workers ( $n=10)$ : TL 5.64-6.23; HW 1.461.59; HL 1.63-1.72; HS 1.54-1.65; PS5 0.24-0.25 (3); PS6 0.24 (3); EL 0.38-0.40; SL 1.37-1.43; SW 0.13-0.14; ML 1.96-2.22; HaL 0.13-0.19; PH 0.51-0.56 (7); PL 0.41-0.45; NH 0.31-0.37 (9); FeL 2.09-2.28. Indices: CI 88-92; SI 90-96; SWI 9-10; EI 25-27; PI 118-130 (7); FeI 141-148; PSI 30-31 (3).

Male. Notes on collecting and identification: A single male collected at light was identified as a specimen of the $C$. cylindrica group. DNA barcoding revealed specific identity with a nest series of $C$. badia from the same botanical garden. The morphological identification of this nest series (Col. 66-4) was carried out by direct comparison to the lectotype of $C$. badia.

Description (Fig. 10): Overall very similar to C. explodens sp. n. and differing by the following characters:

Measurements of male $(\mathrm{n}=1)$ : TL 8.28; HW 1.35; HL 1.26; HS 1.30; PS5 0.20; PS6 0.15; EL 0.48; SL 0.83; SW 0.10; ML 3.07; HaL n.a.; PH 0.47; PL 0.41; NH 0.31; FeL 1.96; OcW 0.19; OED 0.29; OcD 0.46; FWL 7.43; MSW 1.37; 2r 0.41; 4Rs+M 0.37. Indices: CI 107; SI 61; SWI 13; EI 36; PI 116; FeI 145; PSI 26; OI 61; WVI 91.

Structures: Size larger (TL ca. $8.3 \mathrm{~mm}$ ). Integument rather shiny (Fig. 10a, b), especially on mesosoma. Clypeus with distinctly developed median carina, almost reaching anterior margin. Maxillary palpi (PSI 26) and antennal scapes (SI 61) relatively short. First funicular segment slightly more enlarged (30\% wider than the following segment, Fig. 10a). Vein 4Rs+M of forewing long. Petiolar node slightly more widely rounded in lateral aspect. 
Genital structures (Fig. 10c-g) very similar to C. explodens sp. n., with the following exceptions: Gonostylus very narrow, with weaker reticulation of lateral surface (Fig. 10e). Basivolsella with extremely short ventral setae (Fig. 10f). Digitus with rounded apex, without ventroapical corner (Fig. 10f). Valviceps with slightly coarser ventral serration (Fig. 10g).

Colour: Head chiefly dark brown, with lighter area comprising frons between antennal insertions and clypeus. Eyes grey. Ocelli clear, almost colourless. Posterior and anterior clypeal margins, as well as proximal fourth of clypeal carina black. Gaster dark brown. Mesosoma, petiole, mandibles, antennae, and legs lighter brown, appendages becoming yellowish towards apices. Antennal insertions, mandibular bases, margins of thoracic sclerites (especially below tegulae) creamy yellow. Gastral tergites medially with very narrow hyaline margins; sternites with relatively broad posterior margins. Wings hyaline, forewing with a slight brownish tinge and cells along veins, as well as pterostigma darker brownish, all veins pale brown. On hind wing all veins pale yellow.

Pilosity: Appressed and subdecumbent setae comparatively shorter and sparser, but difference less obvious on gaster. Standing setae on mesonotum and gaster shorter, on mesonotum less numerous.

Comparative notes: The male of $C$. badia can be distinguished from males of $C$. explodens sp. n. by larger body size, differing colour pattern, more shiny integument, well-developed clypeal carina, differing proportions of wing venation, and relatively shorter scapes (Fig. 8b). In the genitalia, the most striking differences are in the narrower gonostylus and the more rounded digitus apex (compare Figs 7e, 10f).

\section{Discussion}

\section{Molecular results}

In this study, three mitochondrial DNA loci and one nuclear DNA fragment were applied for the construction of a molecular phylogenetic tree (Fig. 1). The evolutionary analysis based on four loci showed that $C$. explodens sp. $\mathrm{n}$. is clearly genetically distinct from morphologically similar species. A minor level of infraspecific polymorphism within the specimens from Brunei was observed for COI, COII, and in particular for cytB marker. While tree topologies based on single mitochondrial loci were concordant, the cad tree (nuclear locus) was not resolved for the entire COCY group. The comparison of COI sequences with several hundred COCY sequences available in our local database and 13 sequences deposited in NCBI (Nov. 2017) suggests that this marker can be used for the reliable molecular identification (DNA barcoding) of $C$. explodens sp. n., as COI sequences of the nearest COCY taxa share only $91 \%$ similarity (C. badia), and the similarity to the selected non-COCY species C. aruensis is $83 \%$.

The DNA extraction from the gastral parts of the mandibular gland reservoirs of C. explodens sp. n. minor workers resulted in drastically low yields indicating no abundant microbial symbionts present there. The successful 16S rRNA PCR amplification 
gave a sharp band that was sequenced with high reproducibility. The 16S rRNA fragment corresponding to the whole genome sequenced Blochmannia endosymbiont of North American Colobopsis obliquus strain 757 (NCBI GenBank accession number CP010049, Williams and Wernegreen 2015) was $92 \%$ similar to mOTU revealed in this study resulting in 56 polymorphic sites. This confirms that C. explodens sp. n. also harbours these bacteria that usually colonize the midgut of Camponotini workers (Sauer et al. 2002) and are considered to be beneficial for N-nutrition of these ants; they may also contribute to the general health of the workers and gynes. Thus, the detection of cf. Blochmannia bacteria rather indicated the contamination of the MG sample by fragments of the digestive system. In this respect, it is interesting to note that no Wolbachia (Alphaproteobacteria) mOTUs were recovered, but neither digestive tract nor ovaries were specifically investigated.

\section{Taxonomy}

The treatment of Colobopsis as a genus separate from Camponotus is supported by molecular, morphological, and biological data (Blaimer et al. 2015, Ward et al. 2016). Naked pupae (Wheeler 1904; see Suppl. material 5) and presence of phragmotic soldiers and gynes are important features of Colobopsis, although unknown in many of the 94 valid species assigned to this genus by Ward et al. (2016). The morphological separation of minor workers of Colobopsis and Camponotus is chiefly based on head morphology, but complicated by extensive evolutionary changes within each group (Ward et al. 2016); however, the phylogeny of Colobopsis species has not been studied to date. The molecular data published by Blaimer et al. (2015), obtained from only four species, do not allow an interpretation of the relationships of intrageneric clades. Attempts to classify the species by morphological characters (Emery 1925, McArthur 2012), although useful for a rough sorting of species, probably hardly reflect their evolutionary relationships.

A first attempt of a comprehensive classification of the species of Colobopsis (as a subgenus of Camponotus) was done by Carlo Emery. In his outstanding treatment of Formicinae (Emery 1925) he treated 58 species and established six groups to hold 49 of them (nine remained unclassified). He defined the [Camponotus (Colobopsis)] cylindricus group by a gradual variation between worker and soldier, interspecific variation of head in soldiers and females (from concave and marginate to oblique and obtuse), and generally large size. Emery included eight species presently classified as Colobopsis (Ward et al. 2016), of which Colobopsis calva Emery, 1920, C. quadriceps (Smith, 1859), and C. smithiana (Wheeler, 1919) are not presently assigned to this group (see below), whereas $C$. badia and C. corallina were not included (listed under incertae sedis). Although Emery (1925) correctly recognized the size variation of workers, he failed to recognize the unique characteristics of the soldier caste (see Laciny et al. 2017).

More species of the COCY group were subsequently described by Stitz (1925), Menozzi (1926) and Karawajew (1929, 1935). A second attempt at classification was 
made by McArthur (2012): His Camponotus (Colobopsis) cylindricus group consists of species with "neck attached to head well below vertex" and is broader than Emery's (1925) cylindricus group. It includes the following species (according to current classification) that do not fit the characteristics of the COCY group in the present sense: Colobopsis anderseni (McArthur \& Shattuck, 2001), C. brachycephala Santschi, 1920, C. cotesii (Forel, 1893), C. desecta (Smith, 1860), C. excavata (Donisthorpe, 1948), C. hosei (Forel, 1911a), C. mutilata (Smith, 1859), and C. quadriceps, as well as Camponotus dedalus Forel, 1911b, and Camponotus kutteri Forel, 1915.

According to our morphological studies the COCY group can be defined as such: polymorphic Colobopsis with at least three distinct female castes: (i) winged, phragmotic gynes, (ii) phragmotic soldiers (doorkeepers), and (iii) minor workers with a considerable size variation; intermorphic workers may occur in addition (Laciny et al. 2017). Minor workers: Vertex highly raised above foramen. Eyes of minor worker small and flat, not breaking head sides in full-face view. Entire trunk with dense, reticulated microstructures; punctures of integument often reduced. Head with moderate, mesosoma with dense pubescence. Mesosoma (at least the pronotum, except in $C$. clerodendri Emery, 1887) dorsally with long undulated setae, never arranged in distinct rows. Gaster with appressed pubescence and two or three types of setae of different lengths (not arranged in rows, except at hind margin). Soldiers (not known of all taxa): differing from minor workers by enlarged heads and short appendages (antennae, palpi, legs); in most species with a clearly circumscribed head shield for phragmosis. Microsculpture and pilosity similar to minor worker.

Following this definition, the COCY group presently comprises 17 names in the rank of species, subspecies or variations, which are partly in synonymy to each other. The strong intraspecific variation of minor workers, the frequently lacking knowledge on soldiers (or gynes), and the historical descriptions of taxa from different morphs (either workers or gynes) make the species taxonomy a true challenge. A preliminary analysis of morphological and molecular data (unpublished) supports the division of the group into four species complexes (molecular data of one complex not available). We restrict the following analysis to the species of the $C$. saundersi complex, which includes $C$. explodens sp. $\mathrm{n}$. and can be defined by the following combination of characters observable in minor workers and soldiers: head always red or brown (not black); mesosoma moderately elongated and dorsally with some long undulated setae, at least on pronotum; node of petiole without long setae; gastral tergites with dense (in most species strongly transverse) micro-reticulation and with small hair pits (without large grooves). Soldiers and gynes (not known of all species) have a strongly truncated head, in most species with a well-defined (crested) head shield. The following names are available in this group (listed chronologically): Colobopsis badia (Smith, 1857), C. corallina Roger, 1863, C. saundersi Emery, 1889, C. badia var. krama Forel, 1912, C. badia saginata Stitz, 1925, C. solenobia (Menozzi, 1926), and Colobopsis trieterica (Menozzi, 1926), comb. n.

Colobopsis corallina (=C. solenobia syn. n., =C. trieterica syn. n.) is an endemic species from the Philippines. Soldiers and gynes differ strongly from $C$. explodens sp. n. 
and other taxa of the complex (as far as such morphs are known) by a very obtusely margined, not crested head shield. Minors have a bright orange colour on head, mesosoma, and petiole, often extending to gastral tergite I. Morphometrically, the examined minor workers of C. corallina $(\mathrm{n}=31)$ mainly differ from those of $C$. explodens sp. $\mathrm{n}$. by a greater average length of appendages (SI 92-109 vs. 87-104; FeI 136-159 vs. 123-151; PSI 30-39 vs. 28-35).

The greatest similarity is observed between C. explodens sp. n. and C. saginata (stat. n.), a taxon only known from a single alate gyne from Northern Borneo. The important structures of the head shield are almost identical. Although strongly different from C. explodens sp. n. by pale orange brown colour, this gyne differs only by subtle morphometric characters of which the long and distally wide scape seems to be the most reliable (SI 83 vs. 78-80). The length of vein $4 \mathrm{Rs}+\mathrm{M}$ is considerably longer in $C$. saginata than in C. explodens sp. n. (WVI 65 vs. 26-58).

Colobopsis badia var. krama, described from a soldier from Java (Forel 1912) is a very poorly known taxon. We have not been able to study any further material from Java yet. The type (illustrated by AntWeb.org under CASENT0910610) differs from C. explodens sp. n. by a pale red head that strongly contrasts with the dark brown mesosoma, by a well-developed median carina of the head shield that reaches the foremargin of the clypeus, and by a stronger punctation of the preocellar area.

Colobopsis badia was described by Smith (1857) from Singapore and Sarawak (Borneo). However, the original description is too brief to draw any meaningful taxonomic conclusions. Viehmeyer (1916) describes workers of this species in more detail, also noting the secretion of a sticky liquid upon capture. He mentions a strong variability in colouration (from red to almost black with reddish head) and propodeal shape. This raises the question whether all examined specimens were truly members of the same species or perhaps belonged to one of the other, similar species of the $C$. saundersi complex. We examined the three syntype minor workers of $C$. badia in the Oxford University Museum of Natural History. To fix the identity of this taxon, we have chosen the syntype from Singapore (imaged by AntWeb.org under CASENT0901897) as the lectotype of Formica badia. The two syntypes from Sarawak are in a relatively poor condition, which does not allow a complete morphometric analysis, and therefore the conspecificity with the $C$. badia type remains doubtful. We were not successful in obtaining fresh material of C. badia from Singapore, but a nest sample (minors only) from southern Thailand (Trang Province) which agrees well with the lectotype in morphology, especially morphometry, was available for a molecular analysis. It shows that C. badia and C. explodens sp. n. are closely related, but distinct (Fig. 1). Although very similar to C. explodens sp. $\mathrm{n}$. in overall habitus and colouration, the examined $C$. badia minor workers are on average somewhat larger with less size variation (HW 1.22-1.57 vs. $1.46-1.59)$ and possess longer appendages (e.g., FeI 123-151 vs. 141-168; see Fig. 8a).

We examined two syntype minor workers of Colobopsis saundersi from Myanmar ("Tenasserim, Thagata", one illustrated by AntWeb.org under CASENT0905463). Morphometric analysis revealed no differences between the types of $C$. saundersi and C. badia, suggesting that the two species should be synonymized. Colobopsis saundersi 
was considered a junior synonym of $C$. badia by Carlo Emery himself (Emery 1896) but revived from synonymy by Bingham (1903) without providing a reason. The large geographic distance of the type locality of $C$. saundersi and some minor differences in morphology led us to the decision to refrain from a formal synonymization at this time. A comparative molecular analysis of specimens from the type localities (Myanmar, Singapore) would most likely be necessary to corroborate this synonymy.

\section{Morphology of males}

The morphology of males of the tribe Camponotini is insufficiently studied, so that a complete comparison at generic level is not possible. The modified (enlarged) first funicular segment is presumably characteristic for males of Colobopsis. This characteristic has been described in the type species, Colobopsis truncata (Spinola, 1808), by Kutter (1977) and has been equally observed in several species of the C. cylindrica group.

Males of the COCY group have previously been described for three species (see below). However, these descriptions largely lack the necessary details to meaningfully compare taxa. No previous accounts of genital morphology or illustrations of male specimens have been found in the literature.

Colobopsis badia: Viehmeyer (1916) gives a brief description of a male from Singapore. Colouration, size, proportions of head and ocelli, as well as the enlarged first funicular segment correspond well to the examined male from Thailand.

Colobopsis severini (Forel, 1909): The extremely brief description of a male from the island Labuan (near Borneo) is not sufficient to draw any meaningful taxonomic conclusions.

Colobopsis leonardi (Emery, 1889): Karawajew (1929) gives a rather detailed description of males collected within a nest-series on Sumatra. The correct species identification by Karawajew is uncertain; the series may belong to another species of the C. leonardi complex as well. The pattern of pilosity on the gaster, with standing setae only present on the posterior half, also corresponds to our observations in males of the C. saundersi complex.

According to our knowledge, males of the C. cylindrica group can be distinguished from other Southeast Asian Colobopsis species by the relatively rich subdecumbent pilosity and the dense microreticulation of gastral tergites.

\section{Biology}

The behavioural observations on $C$. explodens sp. n. conducted at KBFSC revealed multiple modes of behaviour that are either poorly studied or new to science.

The diurnal activity pattern, as well as the positive influence of high temperatures correspond to the results of previous studies in related taxa (see Hamdan et al. 2013). Similarly large colonies containing several thousand individuals and extend- 
ing to multiple trees and / or artificial nesting structures have also been described for other members of the genus (Federle et al. 1998, Laciny et al. 2017). However, it is still unclear whether individual workers are linked to certain parts of the colony or whether all foragers can move freely through the entire territory of the colony. An interesting and hitherto undescribed phenomenon in this regard is the presence of one or multiple "guards" at the artificial nest's entrance: These minor workers were frequently observed to touch any incoming or leaving workers with their antennae. In some instances, returning foragers were delayed or altogether denied entrance by the guarding ants. One reason for this may be that some workers are linked to different parts of the colony. Alternatively, the observed guarding behaviour may be related to the limited capacity of the artificial nest, which is also suggested by the conspicuously balanced numbers of workers entering and leaving the nest during times of foraging activity. These behavioural patterns are hitherto undescribed and must be investigated in future studies.

A further noteworthy activity observed in foraging workers was so-called "grazing" behaviour, in which minor workers were frequently seen using their mandibles to pluck and chew at various mosses, lichens, and other epiphytes on the bark of trees or other surfaces. While this activity can last for up to one hour at a time, its exact purpose remains unclear. It is possible that minor workers cut and consume parts of the plants and microorganisms or merely ingest fluids. As previous analyses of nitrogen isotopes (Davidson et al. 2016) suggest a largely plant-based diet for COCY ants, it seems likely that "grazing" contributes to their nutrition. However, other previously hypothesized modes of nutrition, such as tending of scale insects (Davidson et al. 2016) were not observed, and recent investigations on Colobopsis leonardi (Emery, 1889) (Zettel et al., ms submitted to Asian Myrmecology) even suggest a higher prevalence of carnivory in COCY ants than previously suspected.

\section{Acknowledgements}

We are thankful to Diane W. Davidson for introducing us to the diversity of Colobopsis cylindrica ants at KBFSC and for passing down her knowledge on the ecology of these organisms. We thank the administration of KBFSC and Universiti Brunei Darussalam (UBD) for project approval and Brunei's Forestry Department for permission to collect ants and use canopy walkways. The authors appreciate the help of UBD and KBFSC staff, especially Salleh Abdullah Bat, Teddy Chua, Masnah Mirasan, Rafhiah Kahar, Roshanizah Rosli, Rodzay Wahab, Chan Chin Mei, and Kushan Tennakoon for facilitating research and fieldwork in many ways. Sincere thanks are due to the authorities of the Khao Chong Botanical Garden, Trang, Thailand, for support and permission for fieldwork. We acknowledge the efforts of Komal Chenthamara (TU Wien, Austria) for her assistance in phylogenetic analysis and Marco Prusa (TU Wien, Austria) for the molecular DNA analysis of MG products. Thanks are owed to Heinz Wiesbauer (Vienna) for providing photographs of living specimens. We thank Sigfrid 
Ingrisch (Bad Karlshafen) for identifying the ant crickets. Finally, thanks are owed to James Hogan (Oxford University Museum of Natural History), Giar-Ann Kung (Natural History Museum of Los Angeles County), Phil Ward (University of California, Davis), and Roberto Poggi and Maria Tavano (Museo Civico di Storia Naturale "Giacomo Doria", Genova) for contributing important specimens. The research was supported by the WWTF LS13-048 grant to ISD.

\section{References}

AntWeb (2017) accessible under http://www.antweb.org [retrieved on 16 March 2017] Bingham CT (1903) The fauna of British India, including Ceylon and Burma. Hymenoptera, Vol. II. Ants and Cuckoo-wasps. Taylor and Francis, London, 506 pp. http://antcat.org/ references/122766

Blaimer BB, Brady SG, Schultz TR, Lloyd MW, Fisher BL, Ward PS (2015) Phylogenomic methods outperform traditional multi-locus approaches in resolving deep evolutionary history: a case study of formicine ants. BMC Evolutionary Biology 15(1): art. 271. https://doi.org/10.1186/s12862-015-0552-5

Bolton B (2017) An online catalog of the ants of the world. http://antcat.org [Accessed: $24^{\text {th }}$ November 2017]

Chen Z, Zhou SY, Ye D, Chen Y, Lu C (2013) Molecular Phylogeny of the Ant Subfamily Formicinae (Hymenoptera, Formicidae) from China Based on Mitochondrial Genes. Sociobiology 60(2): 135-144. https://doi.org/10.13102/sociobiology.v60i2.135-144

Cook SC (2008) Functional and nutritional biology of exudate-feeding ants. PhD Thesis, University of Utah Press, UT, 95 pp.

Davidson DW, Anderson NF, Cook SC, Bernau CR, Jones TH, Kamariah AS, Lim LB, Chan CM, Clark DA (2009) An experimental study of microbial nest associates of Borneo's exploding ants (Camponotus [Colobopsis] species). Journal of Hymenoptera Research 18: 346-360.

Davidson DW, Kopchinskiy A, Salim KA, Grujic M, Lim L, Mei CC, Jones TH, Casamatta D, Atanasova L, Druzhinina IS (2016) Nutrition of Borneo's “exploding” ants (Hymenoptera: Formicidae: Colobopsis): a preliminary assessment. Biotropica 48(4): 518-527. https://doi.org/10.1111/btp.12323

Davidson DW, Lessard JP, Bernau CR, CookSC (2007) The tropical ant mosaic in a primary Bornean rain forest. Biotropica 39: 468-475. https://doi.org/10.1111/j.1744-7429.2007.00304.x

Davidson DW, Salim KA, Billen J (2012) Histology of structures used in territorial combat by Borneo's 'exploding ants'. Acta Zoologica 93(4): 487-491. https://doi.org/10.1111/ j.1463-6395.2011.00523.x

Donisthorpe H (1948) A new species of Colobopsis (Hym., Formicidae) from New Guinea with a few notes on the subgenus. Entomologist's Monthly Magazine 84: 121-122. http://antcat.org/references/124361

Emery C (1887) Catalogo delle formiche esistenti nelle collezioni del Museo Civico di Genova. Parte terza. Formiche della regione Indo-Malese e dell'Australia. [part]. Annali del Museo Civico di Storia Naturale 24: 209-240. http://antcat.org/references/124535 
Emery C (1889) Formiche di Birmania e del Tenasserim raccolte da Leonardo Fea (1885-87). Annali del Museo Civico di Storia Naturale 27: 485-520. www.antwiki.org/wiki/images/4/46/ Emery_1889c.pdf

Emery C (1896) Saggio di un catalogo sistematico dei generi Camponotus, Polyrhachis e affini. Memorie della Reale Accademia delle Scienze dell'Istituto di Bologna (5)5: 363-382. https://archive.org/details/ants_03795

Emery C (1920) Studi sui Camponotus. Bullettino della Società Entomologica Italiana 52: 3-48. https://drive.google.com/drive/folders/0Bwhy_iWDw1a_TEtlam13eEVhb00

Emery C (1925) Hymenoptera. Fam. Formicidae. Subfam. Formicinae. In: Wytsman P (Ed.) Genera Insectorum 183: 1-302. www.antwiki.org/wiki/images/0/07/Emery_1925d.pdf

Fabricius JC (1798) Supplementum entomologiae systematicae. Proft and Storch, Hafniae, 572 pp. https://drive.google.com/drive/folders/0Bwhy_iWDw1a_YkhUbnlzWUJRRWM Federle W, Maschwitz U, Fiala B (1998) The two-partner ant-plant system of Camponotus (Colobopsis) sp. 1 and Macaranga puncticulata (Euphorbiaceae): natural history of the exceptional ant partner. Insectes Sociaux 45: 1-16. https://doi.org/10.1007/s000400050064

Fenn JD, Song H, Cameron SL, Whiting MF (2008) A preliminary mitochondrial genome phylogeny of Orthoptera (Insecta) and approaches to maximizing phylogenetic signal found within mitochondrial genome data. Molecular Phylogenetics and Evolution: 49(1): 59-68. https://doi.org/10.1016/j.ympev.2008.07.004

Forel A (1893) Les Formicides de l'Empire des Indes et de Ceylan. Part II. Journal of the Bombay Natural History Society 7: 430-439. http://antcat.org/references/125050

Forel A (1909) Fourmis du Musée de Bruxelles. Fourmis de Benguela récoltées par M. Creighton Wellman, et fourmis du Congo récoltées par MM. Luja, Kohl et Laurent. Annales de la Société Entomologique de Belgique 53: 51-73. http://www.antcat.org/references/125190

Forel A (1911a) Fourmis de Bornéo, Singapore, Ceylan, etc. récoltées par MM. Haviland, Green, Winkler, Will, Hose, Roepke et Waldo. Revue Suisse de Zoologie 19: 23-62. http://antcat.org/references/125209

Forel A (1911b) Ameisen aus Java beobachtet und gesammelt von Herrn Edward Jacobson. II. Theil. Notes from the Leyden Museum 33: 193-218. http://antcat.org/references/125210 Forel A (1912) Ameisen aus Java beobachtet und gesammelt von Edward Jacobson. III. Theil. Notes from the Leyden Museum 34: 97-112. http://www.antcat.org/references/125227

Forel A (1915) Fauna Simalurensis. Hymenoptera Aculeata, Fam. Formicidae. Tijdschrift voor Entomologie 58: 22-43. http://antcat.org/references/125257

Hamdan MAA, Dawood M, Mahsol HH, Yahya BE (2013) Circadian pattern of Camponotus saundersi (Hymenoptera: Formicidae) in Tropical Rain Forest of Danum Valley, Sabah (Malaysia). Serangga 18(2): 61-72.

Heckenhauer J, Samuel R, Ashton PS, Turner B, Barfuss MHJ, Jang TS, Temsch EM, McCann J, Salim KA, Attanayake AMAS, Chase MW (2017) Phylogenetic analyses of plastid DNA suggest a different interpretation of morphological evolution than those used as the basis for previous classifications of Dipterocarpaceae (Malvales). Botanical Journal of the Linnean Society 185: 1-26. https://doi.org/10.1093/botlinnean/box044

Ingrisch S (1995) Eine neue Ameisengrille aus Borneo (Ensifera: Grylloidea). Entomologische Zeitschrift 105(21): 421-427. https://www.researchgate.net/profile/Sigfrid_Ingrisch/ 
publication/266503742_Eine_neue_Ameisengrille_aus_Borneo_Ensifera_Grylloidea/ links/5531f4a90cf27acb0deaaf55.pdf

Jones TH, Clark DA, Edwards AA, Davidson DW, Spande TF, Snelling RR (2004) The chemistry of exploding ants, Camponotus spp. (cylindricus complex). Journal of chemical ecology 30(8): 1479-1492. https://doi.org/10.1023/B:JOEC.0000042063.01424.28

Karawajew W (1929) Ameisen aus dem Indo-Australischen Gebiet. VI. Trudy FizychnoMatematychnogo Viddilu Vseukrains'kej Akademiyi Nauk 13(1): 235-248. www.antwiki.org/ wiki/images/f/f9/Karavaiev_1929e.pdf

Karawajew W (1933) Ameisen aus dem Indo-Australischen Gebiet, VII. Konowia 11: 305-320. http://antcat.org/references/126272

Karawajew W (1935) Neue Ameisen aus dem Indo-Australischen Gebiet, nebst Revision einiger Formen. Treubia 15: 57-118. http://www.antcat.org/references/126276

Kutter H (1977) Hymenoptera, Formicidae. Insecta Helvetica. Fauna 6: 1-298.

Laciny A, Zettel H, Metscher B, Kamariah AS, Kopchinskiy A, Pretzer C, Druzhinina IS (2017) Morphological variation and mermithism in female castes of Colobopsis sp. nrSA, a Bornean "exploding ant" of the Colobopsis cylindrica group (Hymenoptera: Formicidae). Myrmecological News 24: 91-106. https://myrmecologicalnews.org/cms/index.php?option=com_content \&view $=$ category\&id $=1475 \&$ Itemid $=406$

Latreille PA (1802) Histoire naturelle des fourmis, et recueil de mémoires et d'observations sur les abeilles, les araignées, les faucheurs, et autres insectes. L'imprimerie de Crapelet, Paris, 445 pp. https://drive.google.com/drive/folders/0Bwhy_iWDw1a_Q3YxMi1qVzRsaUU

Leaché AD, Reeder TW (2002) Molecular systematics of the Eastern Fence Lizard (Sceloporus undulatus): a comparison of Parsimony, Likelihood, and Bayesian approaches. Systematic Biology 51: 44-68. https://doi.org/10.1080/106351502753475871

Lefort V, Longueville JE, Gascuel O (2017) SMS: Smart Model Selection in PhyML. Molecular Biology and Evolution 34(9): 2422-2424. https://doi.org/10.1093/molbev/msx149

Maschwitz U, Maschwitz E (1974) Platzende Arbeiterinnen: eine neue Art der Feindabwehr bei sozialen Hautflüglern. Oecologia 14(3): 289-294. https://doi.org/10.1007/BF01039798

McArthur AJ (2012) A guide to Colobopsis ants of the world. South Australian Museum, Adelaide, $234 \mathrm{pp}$.

McArthur AJ, Shattuck SO (2001) A taxonomic revision of the Camponotus macrocephalus species group (Hymenoptera: Formicidae) in Australia. Transactions of the Royal Society of South Australia 125: 25-43. http://antcat.org/references/131861

Menozzi C (1926) Nuove formiche delle isole Filippine e di Singapore. Atti della Società dei Naturalisti e Matematici di Modena 56: 92-103. http://antcat.org/references/127332

Rambaut A (2016) FigTree v.1.4.3. http://tree.bio.ed.ac.uk/software/figtree/

Roger J (1863) Die neu aufgeführten Gattungen und Arten meines Formiciden-Verzeichnisses nebst Ergänzung einiger früher gegebenen Beschreibungen. Berliner Entomologische Zeitschrift 7: 131-214. https://doi.org/10.1002/mmnd.18630070116

Ronquist F, Teslenko M, van der Mark P, Ayres DL, Darling A, Höhna S, Larget B, Liu L, Suchard MA, Huelsenbeck JP (2012) MrBayes 3.2: efficient Bayesian phylogenetic inference and model choice across a large model space. Systematic Biology 61: 539-542. https://doi. org/10.1093/sysbio/sys029 
Russell JA, Funaro CF, Giraldo YM, Goldman-Huertas B, Suh D, Kronauer DJC, Moreau CS, Pierce NE (2012) A Veritable Menagerie of Heritable Bacteria from Ants, Butterflies, and Beyond: Broad Molecular Surveys and a Systematic Review. PLoS ONE 7 (12): e51027. https://doi.org/10.1371/journal.pone.0051027

Santschi F (1920) Cinq nouvelles notes sur les fourmis. Bulletin de la Société Vaudoise des Sciences Naturelles 53: 163-186. http://antcat.org/references/128325

Sauer C, Dudaczek D, Hölldobler B, Gross R (2002) Tissue Localization of the Endosymbiotic Bacterium "Candidatus Blochmannia floridanus" in Adults and Larvae of the Carpenter Ant Camponotus floridanus. Applied and Environmental Microbiology 68(9): 4187-4193. https://doi.org/10.1128/AEM.68.9.4187-4193.2002.

Schimmer F (1911) Eine neue Myrmecophila-Art aus den Vereinigten Staaten (Orth.). Bemerkungen über neue Fundorte und Wirtsameisen von $M$. acervorum, M. ochracea und $M$. salomonis. Entomologische Zeitschrift 25: 443-448.

Schlick-Steiner BC, Steiner FM, Seifert B, Stauffer C, Christian E, Crozier RH (2010) Integrative taxonomy: a multisource approach to exploring biodiversity. Annual review of entomology 55: 421-438. https://doi.org/10.1146/annurev-ento-112408-085432

Shorter JR, Rueppell O (2012) A review on self-destructive defense behaviors in social insects. Insectes Sociaux 59(1): 1-10. https://doi.org/10.1007/s00040-011-0210-x

Smith F (1857) Catalogue of the hymenopterous insects collected at Sarawak, Borneo; Mount Ophir, Malacca; and at Singapore, by A. R. Wallace. [part]. Journal and Proceedings of the Linnean Society of London. Zoology 2: 42-88. http://antcat.org/references/128683

Smith F (1859) Catalogue of hymenopterous insects collected by Mr. A. R. Wallace at the islands of Aru and Key. [part]. Journal and Proceedings of the Linnean Society of London. Zoology 3: 132-158. https://doi.org/10.1111/j.1096-3642.1857.tb01759.x

Smith F (1860) Catalogue of hymenopterous insects collected by Mr. A. R. Wallace in the islands of Bachian, Kaisaa, Amboyna, Gilolo, and at Dory in New Guinea. Journal and Proceedings of the Linnean Society of London. Zoology 5: 93-143. https://drive.google.com/drive/ folders/0Bwhy_iWDw1a_VXZfZmJDTzZPMWc

Spinola M (1808) Insectorum Liguriae species novae aut rariores, quae in agro ligustico nuper detexit, descripsit et iconibus illustravit Maximilianus Spinola, adjecto catalogo specierum auctoribus jam enumeratarum, quae in eadam regione passim occurrent. Tom. II. Fasc. 4. Y. Gravier, Genova, 261 pp. https://drive.google.com/drive/folders/0Bwhy_iWDw1a_ VXZfZmJDTzZPMWc

Stitz H (1925) Ameisen von den Philippinen, den malayischen und ozeanischen Inseln. Sitzungsberichte der Gesellschaft Naturforschender Freunde zu Berlin 1923: 110-136. http://www.antcat.org/references/129040

Ward PS, Brady SG, Fisher BL, Schultz TR (2010) Phylogeny and biogeography of dolichoderine ants: effects of data partitioning and relict taxa on historical inference. Systematic Biology 59(3): 342-362. https://doi.org/10.1093/sysbio/syq012

Ward PS, Blaimer BB, Fisher BL (2016) A revised phylogenetic classification of the ant subfamily Formicinae (Hymenoptera: Formicidae), with resurrection of the genera Colobopsis and Dinomyrmex. Zootaxa 4072: 343-357. http://doi.org/10.11646/zootaxa.4072.3.4 
Viehmeyer H (1916) Ameisen von Singapore. Beobachtet und gesammelt von H. Overbeck. Archiv für Naturgeschichte (A) 81(8): 108-168. http://antcat.org/references/129530

Weisburg WG, Barns SM, Pelletier DA, Lane DJ (1991) 16S ribosomal DNA amplification for phylogenetic study. Journal of Bacteriology 173: 697-703. https://doi.org/10.1128/ jb.173.2.697-703.1991

Wheeler WM (1904) The American ants of the subgenus Colobopsis. Bulletin of the American Museum of Natural History 20: 139-158. http://hdl.handle.net/2246/623

Wheeler WM (1919) The ants of Borneo. Bulletin of the Museum of Comparative Zoology 63: 43-147. http://antcat.org/references/130136

Williams LE, Wernegreen JJ (2015) Genome evolution in an ancient bacteria-ant symbiosis: parallel gene loss among Blochmannia spanning the origin of the ant tribe Camponotini. PeerJ 3: e881. https://doi.org/10.7717/peerj.881

Yu WB, Huang PH, Ree R, Liu ML, Li DZ, Wang H (2011) DNA barcoding of Pedicularis L. (Orobanchaceae): Evaluating four universal barcode loci in a large and hemiparasitic genus. Journal of Systematics and Evolution 49(5): 425-437. https://doi.org/10.1111/ j.1759-6831.2011.00154.x

\section{Supplementary material I}

Figure S1. Living workers of $C$. explodens sp. n. on a detached branch containing a nest fragment

Authors: Laciny A, Zettel H, Kopchinskiy A, Pretzer C, Pal A, Salim KA, Rahimi MJ, Hoenigsberger M, Lim L, Jaitrong W, Druzhinina IS

Data type: multimedia

Explanation note: a Minor worker with characteristically raised gaster $\mathbf{b}$ Major worker with phragmotic head to close nest entrances. Photo: H. Wiesbauer

Copyright notice: This dataset is made available under the Open Database License (http://opendatacommons.org/licenses/odbl/1.0/). The Open Database License $(\mathrm{ODbL})$ is a license agreement intended to allow users to freely share, modify, and use this Dataset while maintaining this same freedom for others, provided that the original source and author(s) are credited.

Link: https://doi.org/10.3897/zookeys.751.22661.suppl1 


\section{Supplementary material 2}

Figure S2. Natural nest of $C$. explodens sp. $n$. in a dead branch in the high canopy of $\boldsymbol{S}$. johorensis (the main host tree for the model colony)

Authors: Laciny A, Zettel H, Kopchinskiy A, Pretzer C, Pal A, Salim KA, Rahimi MJ, Hoenigsberger M, Lim L, Jaitrong W, Druzhinina IS

Data type: multimedia

Explanation note: a Camera setup in the canopy, white arrow marks the nest entrance b, $\mathbf{c}$ Entrance and minor workers.

Copyright notice: This dataset is made available under the Open Database License (http://opendatacommons.org/licenses/odbl/1.0/). The Open Database License $(\mathrm{ODbL})$ is a license agreement intended to allow users to freely share, modify, and use this Dataset while maintaining this same freedom for others, provided that the original source and author(s) are credited.

Link: https://doi.org/10.3897/zookeys.751.22661.suppl2

\section{Supplementary material 3}

Figure S3. Interior of the natural nest of $C$. explodens sp. $n$. found in a dead tree branch of $S$. johorensis on the forest floor

Authors: Laciny A, Zettel H, Kopchinskiy A, Pretzer C, Pal A, Salim KA, Rahimi MJ, Hoenigsberger M, Lim L, Jaitrong W, Druzhinina IS

Data type: multimedia

Explanation note: a Longitudinal section of the nest b Nest cavity. Sawdust is an artefact due to cutting. $\mathbf{c}$ Enlarged view of the nest cavity with a chamber made of dark carton $\mathbf{d}$ Dealate gyne and eggs found inside the chamber shown on $\mathbf{c}$. The nest contained at least three such chambers.

Copyright notice: This dataset is made available under the Open Database License (http://opendatacommons.org/licenses/odbl/1.0/). The Open Database License $(\mathrm{ODbL})$ is a license agreement intended to allow users to freely share, modify, and use this Dataset while maintaining this same freedom for others, provided that the original source and author(s) are credited.

Link: https://doi.org/10.3897/zookeys.751.22661.suppl3 


\section{Supplementary material 4}

\section{Figure S4. Autothysis as defensive behaviour in an experimental setting} Authors: Laciny A, Zettel H, Kopchinskiy A, Pretzer C, Pal A, Salim KA, Rahimi MJ, Hoenigsberger M, Lim L, Jaitrong W, Druzhinina IS

Data type: multimedia

Explanation note: A worker of the predatory species Oecophylla smaragdina is attacked by three minor workers of $C$. explodens sp. n.; all four animals died after the encounter. Black arrows indicate the yellow secretion expelled by rupture of the mandibular gland reservoirs.

Copyright notice: This dataset is made available under the Open Database License (http://opendatacommons.org/licenses/odbl/1.0/). The Open Database License $(\mathrm{ODbL})$ is a license agreement intended to allow users to freely share, modify, and use this Dataset while maintaining this same freedom for others, provided that the original source and author(s) are credited.

Link: https://doi.org/10.3897/zookeys.751.22661.suppl4

\section{Supplementary material 5}

Figure S5. Pupa of $C$. explodens sp. $\mathbf{n}$. found inside the opened natural nest

Authors: Laciny A, Zettel H, Kopchinskiy A, Pretzer C, Pal A, Salim KA, Rahimi MJ, Hoenigsberger M, Lim L, Jaitrong W, Druzhinina IS

Data type: multimedia

Explanation note: Note the absence of a pupal cocoon which is diagnostic for Colobopsis.

Copyright notice: This dataset is made available under the Open Database License (http://opendatacommons.org/licenses/odbl/1.0/). The Open Database License $(\mathrm{ODbL})$ is a license agreement intended to allow users to freely share, modify, and use this Dataset while maintaining this same freedom for others, provided that the original source and author(s) are credited.

Link: https://doi.org/10.3897/zookeys.751.22661.suppl5 


\section{Supplementary material 6}

\section{Table S6.}

Authors: Laciny A, Zettel H, Kopchinskiy A, Pretzer C, Pal A, Salim KA, Rahimi MJ, Hoenigsberger M, Lim L, Jaitrong W, Druzhinina IS

Data type: specimens data

Explanation note: "measurements": Complete dataset of measurements, indices, locality data and type status of all measured specimens of C. explodens sp. $\mathrm{n}$.

"activity": Activity of minor workers of $C$. explodens sp. n. at the entrance of the artificial nest \#38.

"accession numbers": Complete list of accession numbers at NCBI GenBank for all organisms treated in this study.

Copyright notice: This dataset is made available under the Open Database License (http://opendatacommons.org/licenses/odbl/1.0/). The Open Database License $(\mathrm{ODbL})$ is a license agreement intended to allow users to freely share, modify, and use this Dataset while maintaining this same freedom for others, provided that the original source and author(s) are credited.

Link: https://doi.org/10.3897/zookeys.751.22661.suppl6

\section{Supplementary material 7}

Video S7. Video depicting habitat, nesting sites and behaviour of $C$. explodens sp. $\mathbf{n}$. Authors: Laciny A, Zettel H, Kopchinskiy A, Pretzer C, Pal A, Salim KA, Rahimi MJ, Hoenigsberger M, Lim L, Jaitrong W, Druzhinina IS

Data type: multimedia

Explanation note: Video depicting habitat, nesting sites and behaviour of $C$. explodens sp. n. accessible under http://explodingants.com/index.php/publications/colobopsis-explodens

Copyright notice: This dataset is made available under the Open Database License (http://opendatacommons.org/licenses/odbl/1.0/). The Open Database License $(\mathrm{ODbL})$ is a license agreement intended to allow users to freely share, modify, and use this Dataset while maintaining this same freedom for others, provided that the original source and author(s) are credited.

Link: https://doi.org/10.3897/zookeys.751.22661.suppl7 